\title{
Synthesis and applications of nano-structured iron oxides/hydroxides - a review
}

\author{
M. Mohapatra* and S. Anand** \\ Institute of Minerals and Materials Technology, Bhubaneswar, Orissa, INDIA \\ ** Presently Murdoch University, Western Australia \\ *E-Mail: mamatamohapatra@yahoo.com
}

\begin{abstract}
The nano iron oxides have been synthesized by almost all the known wet chemical methods which include precipitation at ambient/elevated temperatures, surfactant mediation, emulsion/micro-emulsion, electro-deposition etc. Iron oxides in nano-scale have exhibited great potential for their applications as catalytic materials, wastewater treatment adsorbents, pigments, flocculants, coatings, gas sensors, ion exchangers, magnetic recording devices, magnetic data storage devices, toners and inks for xerography, magnetic resonance imaging, bioseparation and medicine. Nano sized magnetite $\mathrm{Fe}_{3} \mathrm{O}_{4}$, and maghemite $\gamma-\mathrm{Fe}_{2} \mathrm{O}_{3}$ exhibiting excellent magnetic properties find applications for biomedical purposes and as soft ferrites. Iron hydroxides and oxyhydroxides such as ferrihydrite, goethite, akaganeite, lepidocrocite are being evaluated for their applications in water purification for the removal of toxic ions. Hematite, $\alpha-\mathrm{Fe}_{2} \mathrm{O}_{3}$ in the nano range has been used to obtain transparent paints. In catalysis both iron oxides and hydroxides find application in numerous synthesis processes. This review outlines the work being carried out on synthesis of iron oxides in nano form and their various applications.
\end{abstract}

Keywords: nano iron oxides, synthesis, catalysts, magnetic properties, biomedical application

\section{Introduction}

Iron oxides are one of the most important transition metal oxides of technological importance. Sixteen pure phases of iron oxides, i.e., oxides, hydroxides or oxy-hydroxides are known to date. These are $\mathrm{Fe}(\mathrm{OH})_{3}, \mathrm{Fe}(\mathrm{OH})_{2}, \mathrm{Fe}_{5} \mathrm{HO}_{8} \cdot 4 \mathrm{H}_{2} \mathrm{O}, \mathrm{Fe}_{3} \mathrm{O}_{4}, \mathrm{FeO}$, five polymorphs of $\mathrm{FeOOH}$ and four of $\mathrm{Fe}_{2} \mathrm{O}_{3}$. Characteristics of these oxide compounds include mostly the trivalent state of the iron, low solubility and brilliant colors (Cornell and Schwertmann, 1996). All the iron oxides are crystalline except Schwertmannite and ferrihydrite which are poorly crystalline. These oxides can be synthesized by all known wet chemical methods but to tailor the particle size in nano range and morphology towards a particular application still remains a challenging task. Some of the synthesis techniques include chemical precipitation, sol-gel, hydrothermal, surfactant mediated-precipitation, emulsion-precipitation, microemulsion -precipitation, electro-deposition, and micro wave assisted hydrothermal technique. These oxides find applications as catalysts, sorbents, pigments, flocculants, coatings, gas sensors, ion exchangers and for lubrication (Miyata et al., 1978; Lim et al., 1983; Sharrock and Bodnar,1985; Catlow, 1988; Schwertman and Taylor, 1989; Vissokov and Pirgov,1996; Sestier, 1998; Choo and Kang, 2003). Iron oxide nano-composites have potential applications in areas such as magnetic recording, magnetic data storage devices, toners and inks for xerography, and magnetic resonance imaging, wastewater treatment, bioseparation, and medicine (Raj and Moskovitz, 1990; Pieters et al., 1992; Sun et al., 1992; Ziolo et al., 1992; Safarík, 1995; Häfeli et al.,1997; Schütt et al., 1997; Gazeau et al., 1998; Denizli and Say 2001). Below a critical size, $\mathrm{Fe}_{2} \mathrm{O}_{3}$ nanoparticles can be used for niche applications like transparent iron oxide pigments, due to their durability, shade, UV absorption and added value (Silber et al. 2002). Careful control of the preparation process of transparent iron oxide pigments results in the formation of pigments with very small primary particle sizes. When fully dispersed, they do not scatter light and are hence completely transparent. A brief literature scan is reported in the present review considering the application of various forms of nano iron oxides in the above fields. 


\section{Basic structure of some of the iron oxides}

The term 'ferrihydrite' is often used to describe both 2- or 6-line ferrihydrite, which have either two or six identifiable broad reflections in a diffraction pattern. Different chemical formulae for ferrihydrite are: $\mathrm{Fe}_{5} \mathrm{HO}_{8} \cdot 4 \mathrm{H}_{2} \mathrm{O}, \mathrm{Fe}_{5}\left(\mathrm{O}_{4} \mathrm{H}_{3}\right)_{3}$, $\mathrm{Fe}_{2} \mathrm{O}_{3} \cdot 2 \mathrm{FeOOH} \cdot 2.6 \mathrm{H}_{2} \mathrm{O}$ and $5 \mathrm{Fe}_{2} \mathrm{O}_{3} \cdot 9 \mathrm{H}_{2} \mathrm{O}$. The morphology of ferrihydrite is spherical and unlike other iron oxides it exists only as nano crystals resulting in high specific surface areas ranging from $100-700 \mathrm{~m}^{2} / \mathrm{g}$ (Cornell and Schwertmann, 2003). The structure of ferrihydrite is still under debate as the low degree of order impedes the elucidation of the structure.

$\mathrm{FeO}$, 'wustite' crystallizes in the sodium chloride structure containing four formula units in the cubic unit cell. The large $\mathrm{O}^{2-}$ anions form a close packed fcc sublattice with the small $\mathrm{Fe}^{2+}$ cations located in the interstitial sites. All iron ions are octahedrally coordinated to oxygen. Under thermal equilibrium this phase is stable only at low pressures and for temperatures above $843 \mathrm{~K}$.. In this oxide the oxygen and iron (111) planes form ideal two-dimensional hexagonal lattices with an inter-atomic distance of $3.04 \mathrm{~A}$, which corresponds to the lattice constant of the hexagonal unit cell on the unreconstructed $\mathrm{FeO}(111)$ surface. Along the (111) direction the iron and oxygen (111) planes form the cubic ABC stacking sequence with an interlayer distance of $1.25 \mathrm{~A}$. The ironoxygen bond length is $2.16 \mathrm{~A}$.

Goethite, $\alpha-\mathrm{FeO}(\mathrm{OH})$ exhibits an orthorhombic symmetry, space group Pnma (№ 62). Crystal parameters are: $a=9.95 \AA, b=$ $3.01 \AA, c=4.62 \AA$. The structure could be described as a three-dimensional structure built up with $\mathrm{FeO}_{3}(\mathrm{OH})_{3}$ octahedra which form large tunnels, spreading out along the direction (010) and where hydrogen atoms are located. Each octahedron is linked to eight neighboring octahedral by four edges and three vertices. Oxygen atoms are in tetrahedral surroundings, either $\mathrm{OFe}_{3} \mathrm{H}$ or $\mathrm{OFe}_{3} \mathrm{H}$ (bond). Although goethite displays a range of shapes, the basic morphology is acicular. The specific surface area range from $8-200 \mathrm{~m}^{2} / \mathrm{g}$ (Cornell and Schwertmann, 2003).

Among the iron compounds, the iron oxyhydroxide phase 'akaganeite', $\beta$-FeOOH, has a large tunnel-type structure where iron atoms are strongly bonded to the framework. Generally Akaganeite contains some $\mathrm{Cl}^{-}$as an impurity. In akaganeite the octahedral sites are occupied by $\mathrm{FeH}$, and $\mathrm{Cl}$ (and perhaps $\mathrm{H}_{2} 0$ ) is presumably located in the tunnels. Charges are balanced by substituting $\mathrm{OH}^{-}$for $0_{2}^{-}$.

The crystal structure of 'lepidocrocite' $\gamma-\mathrm{FeO}(\mathrm{OH})$ is built by double layers of Fe-octahedra, with the hydroxyl groups being located on their external surfaces and providing hydrogen bonding between the layers. It is assumed that hydrogen atoms occupy the centers of inversion and are located at the same distances from two oxygen atoms of the adjacent layers, thus forming continuous $\mathrm{O}-\mathrm{H}-\mathrm{O}-\mathrm{H}-\mathrm{O}$ chains with symmetric hydrogen bonds. The basic morphologies of lepidocrocite are lath-like or tabular and the specific surface area range from $15-260 \mathrm{~m}^{2} / \mathrm{g}$ (Cornell and Schwertmann, 2003).

Magnetite $\left(\mathrm{Fe}_{3} \mathrm{O}_{4}\right)$ is a black, ferromagnetic mineral containing both $\mathrm{Fe}(\mathrm{II})$ and $\mathrm{Fe}(\mathrm{III})$. In stoichiometric magnetite $\mathrm{Fe}(\mathrm{II}) / \mathrm{Fe}(\mathrm{III})$ $=0.5$ but magnetite is often non-stoichiometric resulting in a cation deficient Fe(III) layer. The crystal structure of magnetite is inverse spinel with a unit cell consisting of 32 oxygen atoms in a face-centered cubic structure and a unit cell edge length of 0.839 nm. In this crystal structure Fe (II) ions and half of the Fe (III) ions occupy octahedral sites and the other half of the Fe(III) occupies tetrahedral sites. Divalent iron atoms prefer to occupy octahedral sites to have a higher Crystal Field Stabilization Energy (CFSE), whilst the trivalent iron atoms has a CFSE $=0$ in both octahedral and tetrahedral sites. The crystal forms of magnetite include octahedron and rhombodecahedron and the specific surface area ranges from $4-100 \mathrm{~m}^{2} / \mathrm{g}$ (Cornell and Schwertmann, 2003).

The structure of 'hematite', $\alpha-\mathrm{Fe}_{2} \mathrm{O}_{3}$, is isostructural with corundum, $\alpha-\mathrm{Al}_{2} \mathrm{O}_{3}$. The structure has also a three-dimensional framework built up with trigonally distorted octahedra $\mathrm{FeO}_{6}$, linked to thirteen neighbors by one face, three edges and six vertices. The space group is R3 c (No 167, rhombohedral symmetry) and the lattice parameters given in the hexagonal cell are: $a=5.0346$ $\AA, c=13.752 \AA$. The structure is similar to that of corundum, and consists essentially of a dense arrangement of $\mathrm{Fe}^{3+}$ ions in octahedral coordination with oxygens in hexagonal closest-packing. The structure can also be described as the stacking of sheets of octahedraly (six-fold) coordinated $\mathrm{Fe}^{3+}$ ions between two closed-packed layers of oxygens. Since $\mathrm{Fe}$ is in a trivalent state (ferric $\mathrm{Fe}$ ), each of the oxygens is bonded to only two Fe ions, and therefore, only two out of three available oxygen octahedrons are occupied. This arrangement makes the structure neutral with no charge excess or deficit. The Fe-O sheets are held together by strong covalent bonds. The crystal system of hematite is hexagonal, but crystals appear in a wide variety of forms. The specific surface area ranges from $10-90 \mathrm{~m}^{2} / \mathrm{g}$ (Cornell and Schwertmann, 2003).

\section{Synthesis}

Synthesis of iron oxides in the nano range for various applications has been an active and challenging area of research during the last two decades. The processes include careful choice of $\mathrm{pH}$, concentration of the reactants, temperature, method of mixing, and rate of oxidation (Domingo et al., 1994). The morphology of the iron oxide particles depends on the competition between several processes like nucleation, growth, aggregation and adsorption of impurities (Cornell and Schwertmann, 1996). However, in many cases it is not possible to precipitate specific iron oxide particles directly in the desired size and shape. Instead, the synthesis must be done by the transformation of another iron oxide precursor particle (Baker et al., 2000). The sensitivity of the preparative method complicates both the reproducibility and scale up of the process. Recently, several colloidal chemical synthetic procedures have been developed to produce mono-disperse nanoparticles of various materials. This includes the classical LaMer mechanism, 
wherein a short burst of nucleation from a supersaturated solution is followed by the slow growth of particles without any significant additional nucleation, thereby achieving a complete separation of nucleation and growth (LaMer and Dinegar, 1950). Synthesis procedure that combines slow, continuous nucleation and fast, autocatalytic surface growth have also been reported (Butter et al., 2005). Further, in several preparative methodologies, agglomeration of the nano-oxide generated takes place on exposure to air. This is prevented by employing surfactants or by capping with organic acids. In general, for the solution-based synthesis of iron oxide colloids and nanoparticles several techniques such as chemical precipitation, sol-gel processes, forced hydrolysis, hydrothermal synthesis, electrochemical preparation methods (Ozaki et al., 1984; Blesa and Matijevic, 1989; Ozaki et al., 1990; Sugimoto and Sakata, 1992; Sugimoto et al., 1993; Yitai et al., 1994; Sahu et al., 1997; Li et al.,1998; Jungk and Feldmann, 2000; Butter et al., 2005) surfactant mediated or template synthesis, emulsion/ microemulsion methods have been reported. The following sections briefly review the synthesis techniques.

\subsection{Chemical precipitation}

The precipitation technique is probably the simplest and most efficient chemical pathway to obtain iron oxide particles. Iron oxides ( $\mathrm{FeOOH}, \mathrm{Fe}_{3} \mathrm{O}_{4}$ or $\gamma$ - $\mathrm{Fe}_{2} \mathrm{O}_{3}$ ) are usually prepared by addition of alkali to iron salt solutions and keeping the suspensions for ageing. The main advantage of the precipitation process is that a large amount of nanoparticles can be synthesized. However, the control of particle size distribution is limited, because only kinetic factors are controlling the growth of the crystal. In the precipitation process, two stages are involved i.e., a short burst of nucleation occurs when the concentration of the species reaches critical super saturation, and then, there is a slow growth of the nuclei by diffusion of the solutes to the surface of the crystal. To produce mono disperse iron oxide nanoparticles, these two stages should be separated; i.e., nucleation should be avoided during the period of growth (Tartaj et al., 2006). Size control of mono dispersed particles must normally be performed during the very short nucleation period, because the final particle number is determined by the end of the nucleation and it does not change during particle growth. A wide variety of factors can be adjusted in the synthesis of iron oxide nanoparticles to control size, magnetic characteristics, or surface properties. A number of studies have dealt with the influence of these different factors (Sjorgren et al., 1994; Weissleder, 1996; Pardoe et al., 2001; Itoh and Sugimoto, 2003; Thapa et al., 2004; Tominaga et al., 2006). The size and shape of the nanoparticles can be tailored with relative success by adjusting $\mathrm{pH}$, ionic strength, temperature, nature of the salts (perchlorates, chlorides, sulfates, and nitrates), or the $\mathrm{Fe}(\mathrm{II} / \mathrm{Fe}(\mathrm{III})$ concentration ratio.

Pure goethite was synthesized using $1 \mathrm{M}$ ferric nitrate solution and $10 \mathrm{M}$ sodium hydroxide solutions under controlled conditions. Ferric nitrate solution was vigorously stirred at room temperature with the simultaneous addition of $10 \mathrm{M}$ sodium hydroxide solution until the $\mathrm{pH}$ of the solution reached $12-12.5$. In order to obtain $\mathrm{Cu}, \mathrm{Ni}$ or Co doped goethites, the respective sulphate solutions were mixed with ferric nitrate solution prior to alkali addition. Further studies were carried out to convert the goethite to primarily magnetite (Mohapatra et al., 2003; Mohapatra et al., 2005a). Cerium-doped goethite samples in the nano range were prepared through aqueous precipitation by varying $\mathrm{Ce}(\mathrm{IV}) / \mathrm{Fe}(\mathrm{III})$ atomic ratio in the range of 0.015 to 0.07 (Mohapatra et al., 2005b; Sahoo et al., 2009). Irrespective of the amount of cerium doping, all the samples showed only goethite as the crystalline phase. Doping of cerium in goethite affected the peak positions (positive shift 0.02-0.04), crystallinity and lattice parameters of goethite and perturbed the particle structure of $\alpha-\mathrm{Fe}_{2} \mathrm{O}_{3}$ during transformation process. The lattice image of a typical sample with $\mathrm{Ce}(\mathrm{IV}) / \mathrm{Fe}(\mathrm{III})$ atomic ratio $0.035: 1$, indicated that the goethite grew along $\left(\begin{array}{lll}1 & 1 & 0\end{array}\right)$ plane and there was no separate plane of cerium phases present in goethite structure. On heating the samples to $400^{\circ} \mathrm{C}$, goethite was completely transformed to hematite while the crystallization of $\mathrm{CeO}_{2}$ was only partial. Further calcination to $800^{\circ} \mathrm{C}$ resulted in the formation of two distinct phases of $\mathrm{CeO}_{2}$ and $\alpha-\mathrm{Fe}_{2} \mathrm{O}_{3}$ as observed from XRD pattern. Lattice image of the same sample revealed intergrowth of $\left(\begin{array}{lll}1 & 1 & 1\end{array}\right)$ plane of $\mathrm{CeO}_{2}$ along $\left(\begin{array}{lll}0 & 1 & 2\end{array}\right)$ plane of $\alpha-\mathrm{Fe}_{2} \mathrm{O}_{3}$. However, $\mathrm{CeO}_{2}$ crystallites did not separate from $\alpha-\mathrm{Fe}_{2} \mathrm{O}_{3}$. Nano-structures of $\mathrm{CeO}_{2}-\alpha \mathrm{Fe}_{2} \mathrm{O}_{3}$ oxides were retained even on calcination at $800^{\circ} \mathrm{C}$.

The first controlled preparation of superparamagnetic iron oxide particles using alkaline precipitation of $\mathrm{FeCl}_{3}$ and $\mathrm{FeCl}_{2}$ was performed by Massart (1981). The process engineered by Massart (1981) for rapid synthesis of homogeneous $\gamma-\mathrm{Fe}_{2} \mathrm{O}_{3}$ nanoparticles allowed for coating by a wide range of monomeric species, such as amino acids, R-hydroxyacids (citric, tartaric, and gluconic acids) (Fauconnier et al., 1996) hydroxamate (arginine hydroxamate) ( Fauconnier et al., 1999 ), dimercaptosuccinic acid (DMSA),( Fauconnier et al.,1997) or phosphoryl choline (Denizot et al., 1999). Adding increasing amounts of citrate ions in the Massart process allowed for a decrease in the diameter of citrate-coated nanoparticles from 8 to $3 \mathrm{~nm}$ (Bee et al., 1995). Through such a process of size selection using $\mathrm{NaCl}$ as an extra electrolyte, the size distribution of the $7 \mathrm{~nm}$ citrate nanoparticles obtained by the Massart process could be reduced (Massart et al., 1995; Cabuil et al.,1995). Jolivet (1994) studied the influence of the $\mathrm{Fe}^{2+} / \mathrm{Fe}^{3+}$ ratio on the composition, size, morphology, and magnetic properties of co-precipitated nanoscale particles. Babes et al. (1999) also studied the influence of different parameters, including the iron media and the iron concentration. In their setup, the most important factor is the $\mathrm{Fe}^{2+} / \mathrm{Fe}^{3+}$ molar ratio. The mean size increased with the $\mathrm{Fe}^{2+} / \mathrm{Fe}^{3+}$ ratio, whereas the preparation yield decreased. These results were corroborated by literature data (Massart and Cabuil, 1987; Jolivet et al., 1992; Tronc et al.,1992). The dependence of particle mean size of magnetite upon the acidity and the ionic strength of the precipitation medium has been reported (Vayssie 'res et al.,1998; Jiang et al., 2004; Jolivet, 2000). The higher the $\mathrm{pH}$ and ionic strength, the smaller the particle size and size distribution width will be, because these parameters determine the chemical composition of the crystal surface and consequently the electrostatic surface charge of the particles (Tartaj et al., 2006). Qiu et al. (2000) investigated the dependence of the ionic strength of the reaction solution on the formation of magnetite. The magnetite prepared with the addition of $1 \mathrm{M} \mathrm{NaCl}$ 
aqueous solution created iron oxide nanoparticles $1.5 \mathrm{~nm}$ smaller than those formed without its presence. In addition, these smaller nanoparticles formed in the higher ionic strength solutions displayed lower saturation magnetization $(63 \mathrm{emu} / \mathrm{g})$ than those prepared in $\mathrm{NaCl}$-free solutions $(71 \mathrm{emu} / \mathrm{g}$ ). Many factors may influence the size of the nanoparticles. For example, an increase of the mixing rate tends to decrease the particle size. On the contrary, injection flux rates did not seem to have a preponderant influence on the nanoparticle synthesis. Several researchers report the use of an elevated reaction temperature and suggest its significance in optimal crystal formation (Sun and Zeng, 2002). Bubbling nitrogen gas through the solution not only protected against critical oxidation of the magnetite but also reduced the particle size when compared to methods without oxygen removal (Gupta and Wells, 2004; Kim et al., 2001).

\subsection{Sol-Gel and forced hydrolysis techniques}

Solgel processing route is a wet chemical process for the synthesis of colloidal dispersion of inorganic and organic inorganic hybrid materials. The synthesis of metal oxides by sol-gel synthesis has proven extremely versatile since it allows the formation of a large variety of metal oxides at relatively low temperatures via the processing of metal salt or metal alkoxide precursors. The structure and composition of nano oxides formed by sol-gel method depend on the preparation condition, the nature of the precursors, the ion source and $\mathrm{pH}$. It offers advantages such as: (i) tailor-made materials due to good process control, (ii) homogeneous multicomponent systems due to mixing in liquid medium, (iii) low temperature for materials processing. This process is based on the hydroxylation and condensation of molecular precursors in solution, originating a bsolQ of nanometric particles. Further condensation and inorganic polymerization leads to a three dimensional metal oxide network denominated wet gel. The main parameters that influence the kinetics, growth reactions, hydrolysis, condensation reactions, and consequently, the structure and properties of the gel have been reported (Cannas et al., 1998; Ennas et al., 1998). The Sol-Gel synthesis of iron oxide particles was carried out from condensed ferric hydroxide gels, obtained from $\mathrm{FeCl}_{3}$ solutions in $\mathrm{NaOH}$. After aging the gel at $100^{\circ} \mathrm{C}$ for 8 days, mono-disperse pseudo-cubic $\alpha-\mathrm{Fe}_{2} \mathrm{O}_{3}$ particles were obtained (Sugimoto and Sakata, 1992; Sugimoto et al., 1993). The particles were poly-crystals composed of much smaller subunits. The reaction proceeded through a two-step phase transformation from precipitated $\mathrm{Fe}(\mathrm{OH})_{3}$ gel to a fibrous $\beta-\mathrm{FeOOH}$ and finally to $\alpha-\mathrm{Fe}_{2} \mathrm{O}_{3}$ (Sugimoto and Sakata, 1992).

The widely used method to synthesize iron oxy-hydroxide consists of the hydrolysis of $\mathrm{Fe}^{3+}$ cations. However, aging of the sol prepared by pouring fresh ferric solutions into concentrated $\mathrm{NaOH}$ or $\mathrm{KOH}$ solutions has to take place at $60-80^{\circ} \mathrm{C}$ for a period of time ranging from a few days to several weeks (Pascal et al.,1999). As referred by Cornell and Schwertmann (1996), particles formed by the oxidation of $\mathrm{Fe}^{2+}$ solutions at neutral conditions are usually much less developed and the crystals are smaller than those obtained in alkaline $\mathrm{Fe}^{3+}$ solutions. Moreover, oxidation of the ferrous salt solutions by air bubbling yields one or several of the following products: goethite $(\alpha-\mathrm{FeOOH})$, lepidocrocite $(\gamma-\mathrm{FeOOH})$, magnetite $\left(\mathrm{Fe}_{3} \mathrm{O}_{4}\right)$ and hematite $\left(\alpha-\mathrm{Fe}_{2} \mathrm{O}_{3}\right)$. The crystallization of Fe-oxides are strongly affected by the anions or cations adsorbed by ligand exchange. Furthermore, various phases formed during the oxidation of aqueous ferrous systems suggest that the oxidation rate, which can be influenced by $\mathrm{pH}$, temperature and other additives (anions or cations) present in the system, is the dominant factor in determining the hydrolysis product. For the advanced particulate materials, size and shape are often as crucial as crystal structure in determining the performance. Using the forced hydrolysis technique $\alpha-\mathrm{FeOOH}, \gamma-\mathrm{FeOOH}$, and $\mathrm{Fe}_{3} \mathrm{O}_{4}$ with different morphological properties were produced under a wide variety of synthesis conditions (Domingo et al., 1994). Acicular goethite particles were obtained after aerial oxidation of iron(II) solutions at $20^{\circ} \mathrm{C}-80^{\circ} \mathrm{C}$ in acidic conditions. Depending on the temperature, the length of the particles varied between $0.1-0.5 \mu \mathrm{m}$ and the aspect ratio lay between 5 and 10 .

Polydisperse magnetite micro crystals were prepared in neutral or basic $\mathrm{pH}$ at $90^{\circ} \mathrm{C}$ by the addition of $\mathrm{KNO}_{3}$ to $\mathrm{FeCl}_{2}$ and $\mathrm{KOH}$ solution. Spindle-type colloidal hematite particles of narrow size distribution were prepared in a similar way by forced hydrolysis of ferric chloride solution in the presence of phosphate and hypophosphate at $100^{\circ} \mathrm{C}$ for 2 to 7 days (Ozaki et al., 1984). These hematite particles can easily be converted in maghemite particles of the same size and shape by heating under hydrogen gas flow followed by re-oxidation with air (Ozaki and Matijevic, 1985). Plate-like hematite particles of about $5-10 \mu \mathrm{m}$ in diameter were obtained by aging basic ferric salt solutions in the presence of either EDTA or $\mathrm{KNO}_{3}$ or triethanolamine and hydrazine or hydrogen peroxide (Ozaki et al.,1990).

\subsection{Hydrothermal technique}

Hydrothermal technique is defined as any heterogeneous reaction in the presence of aqueous solvents or mineralizers under high pressure and temperature conditions. Hydrothermal treatment of iron salt could generate iron oxides when the applied conditions are appropriate. The hydrothermal preparation of goethite and hematite from amorphous iron(III) hydroxide was studied at various $\mathrm{pH}$ values in the temperature range $100-200^{\circ} \mathrm{C}$. In the $\mathrm{pH}$ range $8.0-10.0$, goethite and hematite were formed. In the range $10.5-$ 10.8 only goethite was formed, and in the $\mathrm{pH}$ range $0.8-2.6$ hematite was the only reaction product (Christensen, 1968). The decomposition of $\alpha-\mathrm{FeOOH}$ to $\alpha-\mathrm{Fe}_{2} \mathrm{O}_{3}$ in neutral and weakly alkaline hydrothermal solution was observed at $150^{\circ} \mathrm{C} \pm 20^{\circ} \mathrm{C}$, and this temperature was suggested to be the upper temperature for the formation of the $\alpha$-FeOOH minerals. However, the transformation is also strongly $\mathrm{pH}$ dependent so that the transformation temperature increased by $25 \mathrm{~K}$ per $\mathrm{pH}$ unit (Robins, 1967). The first in situ investigation of the rate of crystallization of amorphous iron(III) hydroxide to $\alpha-\mathrm{Fe}_{2} \mathrm{O}_{3}$ and $\alpha-\mathrm{FeOOH}$ was made at hydrothermal conditions using neutron powder diffraction (Axel et al., 2007). Chen et al. (1998) have reported a facile and environmental friendly ultrasonic-assisted hydrothermal route for preparation of goethite flower structures using Fe nano-powders 
at low temperature $\left(85^{\circ} \mathrm{C}\right)$. The flower structure consisted of tens of hundreds of nano wires and such structures could further selfassemble with the flake with micro size area. Structural, morphological, and elemental analysis revealed that the products consisted of flower-like structures with high structural uniformity, good crystal quality, and high yields. Magnetic measurements showed that the as-obtained goethite flowers exhibited weakly ferromagnetic characteristics at room temperature, which were quite different from those of the corresponding bulk materials.

Šaric et al. (1998) discussed the effects of urotropin on the chemical and microstructural properties of Fe-oxide powders prepared by the hydrolysis of aqueous $\mathrm{FeCl}_{3}$ solutions. Hydrothermal treatment of an iron chloride solution together with iron powder in the presence of urea yielded after 20 hours at $130^{\circ} \mathrm{C}-150^{\circ} \mathrm{C}$ ultrafine, short and rod-shaped magnetite particles of about $80 \mathrm{~nm}$ in size and an aspect ratio of about 2 (Yitai et al., 1994). By varying the $\mathrm{pH}$ in the range 3 to 10 and by increasing the reaction temperature up to $180^{\circ} \mathrm{C}$, hematite particles of various shapes and sizes were obtained (Sahu et al., 1997). It was observed that the particle size decreased with an increase in the $\mathrm{pH}$. The prepared particles were all polycrystalline at $\mathrm{pH}$ of $\leq 7.0$. Transmission electron microscopy investigations revealed that the particle morphology strongly depended on the $\mathrm{pH}$ value: at $\mathrm{pH} 3$ very uniform pseudocubic particles of about $0.65 \mathrm{~nm}$ were obtained, and at $\mathrm{pH} 4.5$ the particle size decreases; whereas at $\mathrm{pH} 7 \mathrm{a}$ change in the shape of the particle took place. Ultrafine powders of $\alpha-\mathrm{Fe}_{2} \mathrm{O}_{3}$ and $\mathrm{Fe}_{3} \mathrm{O}_{4}$ were hydrothermally prepared at $150^{\circ} \mathrm{C}$ in the presence of hydrazine ( $\mathrm{Li}$ et al., 1998). Also in this case, the morphology of the iron oxide particles was strongly influenced by the $\mathrm{pH}$ value. The non-agglomerated and spherical particles were homogeneous in morphology with an average size of about 70 nm. $\alpha-\mathrm{Fe}_{2} \mathrm{O}_{3}$ nanowires were successfully prepared by a hydrothermal method and subsequent heat treatment using isopropanol and nitrilotriacetic acid. Liang et al. (2010) synthesized iron oxides using hydrothermal and solvothermal processes. In hydrothermal preparation, $\alpha-\mathrm{Fe}_{2} \mathrm{O}_{3}$ was obtained. The $\alpha-\mathrm{Fe}_{2} \mathrm{O}_{3}$ crystal was suggested to grow in sub-critical water via dissolution and precipitation processes. The $\alpha-\mathrm{Fe}_{2} \mathrm{O}_{3}$ particles synthesized at $420^{\circ} \mathrm{C}$ had a particle size of nearly $40 \mathrm{~nm}$, which is much smaller than particles produced at $350^{\circ} \mathrm{C}(60 \mathrm{~nm})$. Crystalline $\mathrm{Fe}_{3} \mathrm{O}_{4}$ was formed in a solvothermal preparation due to the reducing atmosphere resulting from the oxidation of IPA into acetone. The acetone molecules adsorbed on the $\mathrm{Fe}_{3} \mathrm{O}_{4}$ surfaces were suggested to suppress crystallite growth.

Zheng et al. (2006) reported the synthesis and magnetic properties of hydrothermally prepared $\mathrm{Fe}_{3} \mathrm{O}_{4}$. The hydrothermal synthesis of size controlled $\mathrm{Fe}_{3} \mathrm{O}_{4}$ nanoparticles was carried out by Mizutani et al. (2010) using the starting solution containing lactate and sulfate ions at various concentrations in order to control the particle size. The particle size was controlled by means of the coexistence effects of lactate and sulfate ions. Depending on their concentration, the particle size could be varied from 9.5 to $38.6 \mathrm{~nm}$. Size-controlled and coated magnetite nanoparticles with glucose and gluconic acid were synthesized by Sun et al. (2009) via a simple and facile hydrothermal reduction route using a single iron precursor, $\mathrm{FeCl}_{3}$. The particle size could be easily controlled in the range of 4-16 nm. Sucrose was required for the formation of nanoscale and coated magnetite instead of the much larger hematite. Sucrose acts as a bifunctional agent (i) it decomposes into reducing species, causing partial reduction of the $\mathrm{Fe}^{3+}$ ions to $\mathrm{Fe}^{2+}$ ions as required for the formation of $\mathrm{Fe}_{3} \mathrm{O}_{4}$ and (ii) acts as the source of a capping agent to adjust the surface properties and enable the formation of nanoscale particles.

Selective synthesis of $\alpha-\mathrm{FeOOH}$ and $\alpha-\mathrm{Fe}_{2} \mathrm{O}_{3}$ nanorods was developed by Dong et al. (2009) using ferrous sulphate and hydrogen peroxide as raw materials. Only by adjusting the reaction temperature in hydrothermal synthesis, the $\alpha$-FeOOH nanorods (at $150^{\circ} \mathrm{C}$ ) and $\alpha-\mathrm{Fe}_{2} \mathrm{O}_{3}$ nanorods (at $200{ }^{\circ} \mathrm{C}$ ) were obtained. A facile one-step hydrothermal approach was made by Ge et al. (2009) for the synthesis of iron oxide $\left(\mathrm{Fe}_{3} \mathrm{O}_{4}\right)$ nanoparticles (NPs) with controllable diameters, narrow size distribution, and tunable magnetic properties. The iron oxide NPs were synthesized by oxidation of ferrous chloride in basic aqueous solution under an elevated temperature and pressure. The particles were highly crystalline and that the diameters of the particles could be tuned from 15 to $31 \mathrm{~nm}$ through the variation of the reaction conditions. The NPs exhibited high saturation magnetization in the range of 53.3$97.4 \mathrm{emu} / \mathrm{g}$ and their magnetic behavior was either ferromagnetic or superparamagnetic depending on the particle size. Nanoparticles with a high level of mono dispersity and size control were obtained by high-temperature decomposition of iron organic precursors, such as $\mathrm{Fe}(\mathrm{Cup})_{3}, \mathrm{Fe}(\mathrm{CO})_{5}$, or $\mathrm{Fe}(\mathrm{acac})_{3}$, using organic solvents and surfactants (Hyeon et al., 2001). For example, iron oleate could be formed from decomposition of iron carbonyl in the presence of octyl ether and oleic acid at $100^{\circ} \mathrm{C}$ followed by cooling to room temperature. Then $\left(\mathrm{CH}_{3}\right)_{3} \mathrm{NO}$ was added and the solution was refluxed (Hyeon et al., 2001). Highly crystalline and mono-disperse maghemite crystals were obtained at $100^{\circ} \mathrm{C}$ by thermal decomposition of iron pentacarbonyl in the presence of oleic acid and then aging at $300^{\circ} \mathrm{C}$ the iron oleic complex. This two-step process allowed for the production of selected particles sizes from 4 to $16 \mathrm{~nm}$. Hydrophobic magnetite particles with a narrow size distribution were prepared by thermal decomposition of $\mathrm{Fe}(\mathrm{CO})_{5}$ in octyl ether solution of oleic acid and consecutive aeration (Woo et al., 2005 ). The nanoparticles were converted into a magnetite core/silica shell with hydrophilic and processible aminopropyl groups on their surfaces. Sun et al. (2004) have described a high-temperature reaction of iron(III) acetylacetonate with 1,2-hexadecanediol in the presence of oleic acid and oleylamine to obtain monodisperse magnetite nanoparticles. The particle diameter could be tuned from 4 to $20 \mathrm{~nm}$, and the hydrophobic particles could be transformed into hydrophilic ones by adding a bipolar surfactant. The thermal decomposition of iron pentacarbonyl and iron oleate at different temperatures affords monodisperse nanoparticles ranging from 4 to $11 \mathrm{~nm}$, dispersible in organic solvent (Park et al., 2005).

The use of nontoxic iron chloride salts as a precursor has been proposed by different groups (Jana et al., 2004; Park et al., 2004). The nanoparticles obtained are dispersible in different organic solvents (hexane and toluene) but probably not in water, and sophisticated post preparative methods are required to make these nano crystals water-soluble. Li et al. (2004 a, 2004b, 2005a, 
2005b) have described synthesis route of water-dispersible magnetite in acidic or basic media by thermal decomposition of $\mathrm{Fe}(\mathrm{acac})_{3}$ or inexpensive $\mathrm{FeCl}_{3}$ in refluxing 2-pyrrolidone. Magnetite nanocrystals were synthesized from thermal decomposition of $\mathrm{Fe}(\mathrm{acac})_{3}$ in high boiling organic solvents with a controlled size of 4, 6, 9, and $12 \mathrm{~nm}$. An efficient route for simultaneous synthesis and self-assembly of 3D layered $\beta-\mathrm{FeOOH}$ nano rods was reported by Fang et al. (2010). The nature of particles depended on a pH-induced strategy, in which the continuous change of $\mathrm{pH}$ was achieved by hydrolysis of $\mathrm{FeCl}_{3} \cdot 6 \mathrm{H}_{2} \mathrm{O}$ in the presence of urea under hydrothermal conditions. The electron microscopy observations revealed that the square-prismic $\beta$-FeOOH nano rods were self-assembled in a side-by-side fashion to form highly oriented 2D nano rod arrays, and the 2D nano rod arrays were further stacked in a face-to-face fashion to form the final 3D layered architectures. On the basis of time-dependent experiments, a multistage reaction mechanism for the formation of the $3 \mathrm{D}$ layered $\beta-\mathrm{FeOOH}$ nano rods architecture was presented, involving the fast growth and synchronous self-assembly of the nano rods toward 1D, 2D, and 3D spontaneously.

\subsection{Surfactant mediated/template synthesis}

Supramolecular surfactant-controlled method for the synthesis of mesostructured iron oxides has acquired more importance in recent scenario, which uses neutral or charged template molecules. Hexa-decylsulfonic acid mixed at room temperature with an aqueous solution of $\mathrm{FeCl}_{2}$ yielded a hexagonal structured iron oxide with a d-spacing of $3.75 \mathrm{~nm}$ (Ciesla et al., 1994). In a similar approach, lamellar iron oxide/surfactant composites were produced by the controlled precipitation and hydrolysis of aqueous iron cations into self-assembled iron/surfactant arrays (Tolbert et al., 1997). These composites were obtained by mixing iron(II) or iron(III) salt solutions with diluted aqueous solutions of sodium n-alkyl sulfates at room temperature. Lamellar iron(hydro) oxyhydroxide-surfactant composites were also prepared by adding ammonia to a $\mathrm{FeCl}_{3}$ solution followed by mixing with the sodium n-alkyl sulfate template (Wirnsberger et al., 1998). By adjusting the reaction conditions, composites with inorganic walls from about $10-26 \AA$ were produced in a controllable manner. Not only long-chain surfactant templates can influence the morphology of the iron oxide particles, it is well known that inorganic anions like chloride, phosphate or sulfate have a strong influence on particle size and shape (Livage et al., 1988; Reeves and Mann, 1991). $\alpha-\mathrm{Fe}_{2} \mathrm{O}_{3}$ nanorods and nanotubes have been synthesized (Liu et al., 2006) using different surfactant i.e., polyisobutylene bissuccinimide (L113B) or surfactant Span80. Highquality one dimensional products were obtained with aqueous butanol solution as the solvent and carbamide as the base, giving rise to single-crystalline products at $150^{\circ} \mathrm{C}$.

A microbial-derived surfactant (MDS) (Iijima et al., 2006) with a high carboxyl density and low molecular weight or an artificially synthesised polyacrylic acid sodium salt (PAA) was added to the raw material aqueous solution before iron oxide particle synthesis by gel-sol method. Pseudo-cubic haematite particles with a diameter of $500 \mathrm{~nm}$ were prepared without surfactant addition while spherical size iron oxide nanoparticles of $20 \mathrm{~nm}$ diameter were prepared by MDS addition. Nevertheless, needle shaped iron hydroxide nanoparticles with a length of $100 \mathrm{~nm}$ along the long axis were prepared by PAA addition. The morphology of the iron hydroxide nanoparticles depended on the molecular structure of the surfactants.

A hybrid nano crystalline surfactant modified akaganeite $(\beta-\mathrm{FeOOH})$ sorbent was prepared (Deliyanni et al., 2006) by using iron(III) chloride as the precursor and a cationic surfactant, hexadecyltrimethylammonium bromide (HDTMA) to chemically modify the adsorbent surface by co-precipitation. Yue et al. (2010) demonstrated a CTAB-directed synthesis method for synthesizing well-crystalline goethite nano rods.

\subsection{Biomimetic mineralization}

Bio-mimetic mineralization within protein cages provides an attractive alternative approach for synthesizing mono-disperse nanosized particles. Since maximum particle sizes are limited by the cage inner diameter, reactions carried out in cages can lead to highly mono-disperse size distributions, particularly if nucleation rather than growth is the rate-limiting stage of the synthesis. Control of the size and shape of the particles can be obtained through the use of various distinct protein cages in an expanding library of structures (Douglas and Young, 1998; Douglas and Stark, 2000; Allen et al., 2003; Rice et al., 2004). Finally, the protein shell surrounding particles synthesized by this method provides a framework of amino acid side-chains for further synthetic processing, useful, for example, for forming uniform spatial arrays (Klem et al., 2003).

\subsection{Precipitation by anhydrous solution}

To overcome the limitations introduced by aqueous solution reactions, some researchers have developed anhydrous solution approaches for the production of metal oxide nanoparticles and in particular iron oxide (Rockenberger et al., 1999; Hyeon et al., 2001; Sun and Zeng, 2002; Jing and Wu, 2004; Li et al., 2004c; Nicola et al., 2005). Hyeon et al. (2001) have successfully fabricated highly crystalline and mono-disperse $\gamma-\mathrm{Fe}_{2} \mathrm{O}_{3}$ nanoparticles with a particle size of $13 \mathrm{~nm}$ by direct oxidation of iron pentacarbonyl in the presence of oleic acid with trimethylamine oxide as an oxidant. Jing and $\mathrm{Wu}$ (2004) have synthesized acicular $\gamma-\mathrm{Fe}_{2} \mathrm{O}_{3}$ nanoparticles with a particle size of around $10 \mathrm{~nm}$ using lauric acid as an anhydrous medium. Rockenberger et al. (1999) have also reported that the reaction of $\mathrm{FeCup}_{3}$ with trioctylamine at $300{ }^{\circ} \mathrm{C}$ leads to $6-7 \mathrm{~nm}$ maghemite nanocrystals. Recently, the production of high quality water-soluble iron oxide (WSIO) nanocrystals (Jun et al., 2005) has been reported by thermal decomposition of $\mathrm{Fe}(\mathrm{CO})_{5}$ in hot dioctyl ether. Some of the main difficulties in in-vivo MRI lie in lack of high quality biocompatible magnetic nanocrystals. Therefore, one of the current challenges is how to develop well defined magnetic nanocrystals with optimal nanoscale magnetism, high bio-stability to withstand harsh biological conditions, and the ability to 
escape from the reticulo-endothelial system (RES). For biological application, robust water-soluble nanostructures are necessary, so several synthesis strategies have been used, such as surface functionalization with water-soluble ligands (Chan and Nie, 1998; Jun et al., 2005), silanization (Bruchez Jr. et al., 1998), and encapsulation within block-copolymer micelles (Dubertret et al., 2002; Lee et al., 2005a). On the other hand, adsorption-resistant coatings such as PEG (polyethylene glycol) are often used to minimize recognition by the RES (Gref et al., 1994).

\subsection{Microemulsion technique}

The microemulsion system consists of an oil phase, a surfactant phase and an aqueous phase. Microemulsions are transparent solutions consisting of small droplets of an immiscible phase (non-polar or polar) dispersed in a continuous phase. Surfactants are added to lower the interfacial tension between the immiscible dispersed and continuous phases to stabilize the droplets. Microemulsions may consist of oil-in-water or water-in-oil, depending on the concentration of the different components. By varying the concentration of the dispersed phase and the surfactant, it is possible to tailor the size of the droplets in the range 1-100 nm, approximately. Self-assembled structures of different types can be formed, ranging, for example, from (inverted) spherical and cylindrical micelles to lamellar phases and bicontinuous microemulsions, which may coexist with predominantly oil or aqueous phases (Solans et al., 2005). Microemulsion and inverse micelles route can be employed for obtaining the shape- and size-controlled iron oxide NPs. Geng et al (2006) synthesized $\alpha$-FeOOH nanorods at room temperature by using Pluronic triblock copolymer P123, poly (ethyleneoxide)-block-poly(propyleneoxide)-block-poly(ethyleneoxide) $\left(\mathrm{EO}_{20} \mathrm{PO}_{70} \mathrm{EO}_{20}, \mathrm{Mav}=5800\right)$, and ferric nitrate. The single-crystalline orthorhombic $\alpha$-FeOOH nanorods, growing along $\left(\begin{array}{lll}0 & 0 & 1\end{array}\right)$ direction, were $8.2 \pm 1.5 \mathrm{~nm}$ in diameter and $106 \pm 16 \mathrm{~nm}$ in length. A corresponding mechanism of the formation of $\alpha-\mathrm{FeOOH}$ nanorods was suggested and it was proposed that the surfactant and high basic condition play important roles in the directed growth of $\alpha-\mathrm{FeOOH}$ nanorods. Monodisperse maghemite was synthesized (Vidal-Vidal et al., 2006) by capping with a monolayer coating of oleylamine (or oleic acid). It exhibited narrow size distribution of $3.5 \pm 0.6 \mathrm{~nm}$ and displayed high saturation magnetization values $\left(76.3 \mathrm{Am}^{2} / \mathrm{kg}\right.$ for uncoated NPs, $35.2 \mathrm{Am}^{2} / \mathrm{kg}$ for oleic acid coated NPs, and $33.2 \mathrm{Am}^{2} / \mathrm{kg}$ for oleylamine coated NPs). Chin and Yacob (2007) reported the synthesis of magnetic iron oxide NPs (less than $10 \mathrm{~nm}$ ) via w/o microemulsion. Furthermore, in comparison to the particles produced by Massart's procedure (Tourinho et al., 1990), particles produced by microemulsion technique were smaller in size and showed higher values of saturation magnetization (Chin and Yaacob, 2007). Zhang et al. (2008) fabricated hollow magnetite NPs of 200 to $400 \mathrm{~nm}$ in diameter by the microemulsion route, however these NPs may not be useful for drug delivery purposes. This method suffers from the preparation of adequate crystalline SPIONs on a large scale as the temperature used for such synthesis is low. Lee et al. (2005b) reported synthesis of crystalline maghemite particles with well-defined nanometer sizes by the microemulsion method at high temperature using iron (III) acetyl acetonate as an iron precursor. Sun and Zeng (2002) reported the size controlled synthesis of ultra-small magnetite $(12$ and $16 \mathrm{~nm}) \mathrm{NPs}$ using $\mathrm{Fe}(\mathrm{acac})_{3}$ as an iron source by the microemulsion route. However, despite the presence of surfactants, the aggregation of the produced NPs usually needs several washing processes and further stabilization treatments.

\subsection{Flow injection syntheses}

Reaction zone confinement in different "matrices", such as emulsions, etc., has been used to produce particles with narrow size distributions and, in some cases, to tailor the particle morphology. However, a specific design of the reactor can serve as an alternative to the "matrix" confinement. Alvarez et al. (2006) have developed a novel synthesis of magnetite nanoparticles based on a flow injection synthesis (FIS) technique. The technique consisted of continuous or segmented mixing of reagents under laminar flow regime in a capillary reactor. The FIS technique has some advantages, such as a high reproducibility because of the plug-flow and laminar conditions, a high mixing homogeneity, and an opportunity for a precise external control of the process. The influence of chemical parameters and conditions on the properties of the material was investigated. The obtained magnetite nanoparticles had a narrow size distribution in the range of 2-7 $\mathrm{nm}$.

\subsection{Electrochemical methods}

In this method electrons act as reactant. It is an environmental friendly process with no pollution. However, the costly platinum is used as an electrode and not for reuse in aqueous solution. The electrochemical synthesis of nanosized particles of $\gamma$ - $\mathrm{Fe}_{2} \mathrm{O}_{3}$ of about $20 \mathrm{~nm}$ in non-aqueous medium was reported by Zhang et al. (2007). They used stainless steel plate as anode and cathode respectively, the solvent used can be re-used. Pascal et al. (1999) prepared 3-8 nm maghemite particles by electrochemical method from an iron electrode in an aqueous solution of DMF and cationic surfactants. Here current density controlled the particle size. Electrochemical deposition under oxidizing conditions has been used to prepare nanowires of by Kahn and Petrikowski (2000).

\subsection{Aerosol/vapor methods}

Aerosol technologies, such as spray and laser pyrolysis, are attractive because these technologies are continuous chemical processes allowing for high rate of production (Veintemillas-Verdaguer et al., 2002). In spray pyrolysis, a solution of ferric salts and a reducing agent in organic solvent is sprayed into a series of reactors, where the aerosol solute condenses and the solvent evaporates. The resulting dried product consists of particles whose size depends upon the initial size of the original droplets. Maghemite particles with size ranging from 5 to $60 \mathrm{~nm}$ with different shapes have been obtained using different iron precursor 
salts in alcoholic solution (Veintemillas-Verdaguer et al., 2001; Veintemillas-Verdaguer et al., 2002). Laser pyrolysis can be used to reduce the reaction volume. Laser heats the gaseous mixture of iron precursor and a flowing mixture of gas producing small, narrow size, and non aggregated nano particles. It is a well studied method of obtaining maghemite with particle sizes smaller than $10 \mathrm{~nm}$ (Morales et al., 2003; Veintemillas-Vendaguer et al., 2003). Oscar et al. (2008) reported synthesis of maghemite $\left(\gamma-\mathrm{Fe}_{2} \mathrm{O}_{3}\right)$ nanoparticles by in-situ hard and soft laser decomposition of gaseous $\mathrm{Fe}(\mathrm{CO})_{5}$ in air and by changing the initial $\mathrm{Fe} / \mathrm{O}_{2}$ ratio in the system the particle size could be controlled. Julian-Lopez et al. (2007) have reported the synthesis and characterization of hybrid silica-spinel iron oxide composite microspheres built with superparamagnetic nanoparticles for MRI, hyperthermia, and a hybrid mesoporous matrix, enabling the transport of bioactive molecules. These multifunctional platforms can be obtained by spray drying a sol of tunable composition, allowing for the control of the size and amount of magnetic particles embedded in the matrix.

\subsection{Sonochemical technique}

The sonochemical method has been extensively used to generate novel materials with unusual properties. The chemical effects of ultrasound have been found to be beneficial to form the new phases and are helpful to synthesize highly monodispersive NPs. At very high temperatures, hot spot generated by the rapid collapse of sonically generated cavities allows for the conversion of salts into nanoparticles. Bang and Suslick (2007) reported sonochemical synthesis of nanosized hollow hematite. Vijayakumar et al. (2000) reported a sonochemical synthesis route for preparing pure nanometer-size $\mathrm{Fe}_{3} \mathrm{O}_{4}$ powder with particle size of $10 \mathrm{~nm}$. The prepared $\mathrm{Fe}_{3} \mathrm{O}_{4} \mathrm{NPs}$ were superparamagnetic and the magnetization at room temperature was very low $\left(1.25 \mathrm{emu} \mathrm{g}^{-1}\right)$. Recently Pinkas et al. (2008) developed a sonochemical method for preparing amorphous nanoscopic iron oxide by sonolysis of $\mathrm{Fe}(\mathrm{acac})_{3}$ under Ar with a small amount of added water. The organic content and the surface area of the $\mathrm{Fe}_{2} \mathrm{O}_{3} \mathrm{NPs}$ could be controlled with the amount of water in the reaction mixture, and it increased from $48 \mathrm{~m}^{2} \mathrm{~g}^{-1}$ for dry solvent to $260 \mathrm{~m}^{2} \mathrm{~g}^{-1}$ when wet Ar was employed. The sonolysis of an aqueous solution of $\mathrm{Fe}(\mathrm{CO})_{5}$ in the presence of sodium dodecyl sulfate led to the formation of a stable hydrosol of amorphous $\mathrm{Fe}_{3} \mathrm{O}_{4}$ nanoparticles (Abu and Gedanken, 2005). Superparamagnetic iron oxide nanoparticles (SPIO) having high magnetization and crystallinity have also been synthesized using a sonochemical method (Kim et al., 2005). Ferrofluids from these nanoparticles coated with oleic acid as a surfactant were prepared following the sonochemical methods. The coated SPIO could be easily dispersed in chitosan. The hydrodynamic diameter of the coated SPIO in the chitosan solution was estimated to be $65 \mathrm{~nm}$, and they had a good stability. Shafi et al., (1997) and Kumar et al., (2001) used sonochemical technique to prepare nanoparticles of $\mathrm{Fe}, \mathrm{Fe}_{3} \mathrm{O}_{4}$, and $\mathrm{Fe}_{2} \mathrm{O}_{3}$.

As presented in various subsections on synthesis, it can be observed that with time the synthesis procedures for preparation of iron oxides in nano range have gone through innovation. The major efforts have been devoted to obtain purpose specific particles. With the advancement in development of precision instruments for characterization of surfaces and particle size, it has now become possible to understand the nature of particles in much more details as compared to earlier times. Newer techniques and reagents have been employed for synthesizing nano iron oxides. The advancement has taken place from simple precipitation to surfactant mediation, emulsion, micro-emulsion, hydrothermal Sol-Gel etc. techniques, for obtaining monodispersed nano particles for different applications. Cost effectiveness of any synthesis procedure would depend on the final product and its application, for example, for high end use such as in drug delivery systems, comparatively higher cost of production is tolerable but when the product is to be utilized in mitigation of toxic ions from waste waters, it is essential to use low cost chemicals during synthesis.

\section{Applications}

\subsection{As a colouring and coating material}

The use of hematite and other iron oxides as natural red ceramic pigments has been practiced since prehistoric times. The iron oxides such as magnetite, hematite, maghemite and goethite are commonly used as pigments for black, red, brown and yellow colours respectively. Predominantly natural red iron oxides are used in primers for steel constructions and cars reducing corrosion problems. World consumption of iron oxide pigments comprises of $63 \%$ in synthetic form and $37 \%$ from natural resources. The construction sector - roof tiles, paving slabs and other concrete products - accounts for a major chunk of total world consumption. By reducing the particle size to nano range, transparent iron oxide pigments can be obtained. Manufacturing process of transparent iron oxide pigments depend on the control of physical and surface chemistry properties. Particle size is optimized to ensure that minimal light interference occurs thus maximizing transparency. In general particle size from 2 to $10 \mathrm{~nm}$ increases transparency 310 time when compared to the bulk form (Elizabeth, 1992). Now a days such transparent iron oxide pigments are preferably used. These have good stability to temperature, the red can resist up to $300^{\circ} \mathrm{C}$ while the yellow, black, green and brown can withstand upto $160{ }^{\circ} \mathrm{C}$. These are strong absorbers of ultraviolet radiation (Sreeram et al., 2006) and mostly used in automotive paints, wood finishes, construction paints, industrial coatings, plastic, nylon, rubber and print ink. The excellent weather fastness, UV absorption properties, high transparency and color strength makes trans-oxide to enrich the colors, increase color shades when combined with organic pigments and dyes.

\subsection{As catalyst}

Iron oxide-based materials have been found to be good candidates as cheap and efficient catalysts, especially in environmental catalysis. Miyata et al. (1978)) studied the catalytic activity of several iron oxides and oxide hydroxides of various particle sizes 
for the reduction of 4-nitrotoluene using hydrazine hydrate as reducing agent, and found $\beta$-FeOOH was the most effective catalyst. For oxidation/reduction and acid/base reactions, the most applied iron oxides as catalyst are magnetite and hematite. Nano-particle iron oxide is significantly more effective than conventional micron-sized iron oxide (Walker et al., 1988; Li et al., 2003) for the oxidation of CO and the oxidative pyrolysis of biomass (Li et al., 2003) or biomass model compounds (Li et al., 2004; Shin et al., 2004). These effects could be derived from the high activity of nano-particles that have high BET surface areas and more coordination of unsaturated sites on the surfaces. Chemical and electronic properties, such as phase changes, $\mathrm{OH}$ content, band gap changes etc., could also have contributed to their high reactivity. Iron oxide (usually mixed with other metal oxides) in particular, has been shown to be a very active (although unstable) catalyst for the oxygen evolution process as well as other related processes, such as water splitting, chlorine evolution, the oxidation of organic molecules, the oxygen reduction process and for the hydrogen peroxide decomposition. Even more important are iron oxide-based catalysts in non-electrochemical processes. In nature, nanoparticulate hydrous iron oxide is the iron source for metallo-proteins and therefore stored in form of ferritins in the cells of animals, plants, fungi, and bacteria. The effects of heterogeneous catalyst with iron oxide as one of the phases were used in many important fields. Catalytic activity of nano sized $\mathrm{Au} / \mathrm{Fe}_{2} \mathrm{O}_{3}$ at low temperatures on a $\mathrm{CO}$ oxidation reaction was investigated (Hutchings et al., 2006). The catalytic activities of the $\mathrm{Fe}_{2} \mathrm{O}_{3}$-promoted catalysts for acid catalysis, 2-propanol dehydration, and cumene dealkylation with relation to $\mathrm{Fe}_{2} \mathrm{O}_{3}$ content were investigated by Sohn and Jim (2006). Heterogeneous catalysts based on magnetic mixed iron oxides ( $\mathrm{MO} \cdot \mathrm{Fe}_{2} \mathrm{O}_{3} ; \mathrm{M}$ : $\mathrm{Fe}, \mathrm{Co}, \mathrm{Cu}, \mathrm{Mn}$ ) were used for the discoloring of several synthetic dyes (Baldrian et al., 2006). Multi-walled carbon nanotubes were synthesized employing a $\mathrm{Cr}_{2-} \mathrm{Fe}_{x} \mathrm{O}_{3}$ solid solution as a catalyst (Lima et al., 2006). The $\mathrm{Fe}-\mathrm{Ce}-\mathrm{O}$ solid solutions ( $\mathrm{Fe}, 5-50 \mathrm{~mol} \%$ ) are promising systems for improved $\mathrm{N}_{2} \mathrm{O}$ decomposition catalysts (PerezAlonso et al., 2006). Iron and titanium mixed oxides have been found catalytically active for the reactions of cyclohexane oxidation (Perkas et al., 2001), $\alpha$-pinene oxide isomerization (Neri et al., 2004), O-Cresol photo-degradation (Pal et al., 2001) and formation of dimethyl ether from methanol (Wang and $\mathrm{Ro}$ 2006). $\mathrm{Fe}_{2} \mathrm{O}_{3}$ based nano materials have been developed for the selective catalytic reduction (SCR) of $\mathrm{NO}_{x}$ by $\mathrm{NH}_{3}$ in diesel exhaust (Apostolescu et al., 2001).

\subsection{As gas sensing material}

A number of studies have also been focused on iron oxide $\left(\mathrm{Fe}_{2} \mathrm{O}_{3}\right)$, which, especially in the gamma, cubic phase, exhibits good sensing characteristics towards hydrocarbon gases, carbon monoxide and alcohol (Lee and Choi 1990; Peng and Chai,1993; Siroky et al., 1994; Tianshu et al., 1996; Tao et al., 1999; Lim et al., 2001; Neri et al., 2006). The sensitivity of iron oxide-based sensors can be enhanced by various doping schemes and a number of different dopants such as Pd, Sn, Ti, Zn etc have been used (Kanai et al., 1992; Neri et al., 2002; Reddy et al., 2002; Vasiliev 1992; Tan et al., 2003). While doping is an important factor for controlling the sensing characteristics, the sensor structure, and especially the thickness of its active layer, also has a great influence on the sensitivity. In fact, bulk and thick-film type sensors exhibit a relatively low sensitivity, which substantially improves when the same sensing material is used in a thin-film type sensor. Kaushik et al. fabricated a new glucose biosensor and a urea sensor based on iron oxide nanoparticles-chitosan nano composite (Kaushik et al., 2008; Kaushik et al., 2009). Wang and Tan (2007) have developed a novel amperometric glucose biosensor by immobilizing ferritin antibody on the surface of $\mathrm{Fe}_{3} \mathrm{O}_{4}$ nanoparticles. $\left(\mathrm{Fe}_{3} \mathrm{O}_{4} \mathrm{NPs}\right) /$ chitosan $(\mathrm{Cs})$ composite film modified glassy carbon electrode (GCE) for determination of ferritin. A practical glucose biosensor was developed by Yang et al. (2009) by combining the intrinsic peroxidase-like activity of $\mathrm{Fe}_{3} \mathrm{O}_{4}$ nanoparticles and the anti-interference ability of the nafion film. The modified electrode could virtually eliminate the interference during the detection of glucose. Furthermore, the biosensor was successfully applied to detect glucose in human serum sample. Recently iron oxide nano-particles have also been tested for sensing different toxic biological drug like dopamine (Abolanle et al., 2010). An efficient electro catalytic detection of dopamine was reported using electrodeposited $\mathrm{Fe}_{2} \mathrm{O}_{3}$ nano-particle catalyst supported on a SWCNT (single walled carbon nanotubes)-modified edge-plane pyrolytic graphite electrode (EPPGE) platform (EPPGE-SWCNT- $\mathrm{Fe}_{2} \mathrm{O}_{3}$ ).

\subsection{As impurity control agent}

Iron oxides have relatively high surface area and surface charge, therefore, often regulate free metal and organic matter concentrations in soil or water through adsorption reactions (Barrow et al.,1989; Manceau et al., 2000; Clausen and Fabricius, 2001; Randall et al., 2001). Many toxic cations (Co, $\mathrm{Zn}, \mathrm{Pb}, \mathrm{Cd}, \mathrm{Cs}, \mathrm{U}, \mathrm{Sr}$ etc.) and anions like $\mathrm{AsO}_{4}{ }^{3-}, \mathrm{CrO}_{4}{ }^{2-}, \mathrm{PO}_{4}{ }^{3-}, \mathrm{CO}_{3}{ }^{2-}$ etc. are removed by using various phases of iron oxide (Benjamin and Leckie, 1981; Todorovic et al., 1992; Ding et al., 2000; Zhou et al., 2001; Luengo et al., 2006; Mohapatra et al., 2006). The adsorption properties of the iron oxide is due to combination of both surface compleaxtaion by inner or outer sphere bonding with adsorbate and ion exchange by vader Wall forces. Again the small size of nano particle also gives a high surface area-to-volume ratio, which facilitates interaction with several kinds of chemical species, both gaseous and aqueous (Hiemstra et al., 2004). At the nanoscale these materials are potentially highly efficient for binding metal ions. By tailoring the composition of the metal oxides, one can induce selective adsorption of different metal ions. Use of iron oxide nanoparticles is thus becoming very attractive in the area of adsorption or recovery of metal ions from industrial wastes or natural water streams. Again magnetic separation has been shown to be a useful solid-solid phase separation technique. The problem with magnetic materials is that the particles interact with each other forming large aggregates. However, if the size of the magnetic nanoparticles is reduced to below a few nanometers, they become superparamagnetic. When a magnetic field is applied, the particles acquire a certain magnetization but, because of the high thermal energy, the long range 
order is lost when the field is removed, and the particles have no remanent magnetization (Uheida et al., 2006). This makes magnetic nanoparticles excellent candidates for combining metal binding and selective adsorption properties with ease of phase separation. Recently studies have been reported on removal of cations $\mathrm{Pb}(\mathrm{II}), \mathrm{Cd}(\mathrm{II}), \mathrm{Cu}(\mathrm{II})$ or $\mathrm{Zn}$ by nano structured goethite (Khatun et al., 2007), doped goethite (Mohapatra et al., 2009), ferrihydrite (Mohapatra et al., 2010a) and akaganeite (Mohapatra et al., 2010b) synthesized following different precipitation techniques. Nano goethite (Mohapatra et al., 2010c), nano powders of mixed iron oxides (Mohapatra et al., 2010d) and nano aluminum/iron mixed and pure oxides (Sujana et al., 2009; Sujana et al., 2010) have been reported to be good adsorbents for the removal of fluoride from aqueous solutions and contaminated ground water. $\mathrm{Cu}, \mathrm{Ni}$, or $\mathrm{Co}$ doped nano goethites were found to be quite effective for arsenic removal from aqueous solutions (Mohapatra et al., 2006).

\subsection{As electro magnetic material}

Nanoparticles of magnetic oxides, including most representative ferrites, have been studied for many years for their application as magnetic storage media and ferro-fluids. Over the recent years, gamma iron oxide $\left(\gamma-\mathrm{Fe}_{2} \mathrm{O}_{3}\right)$, a ferromagnetic material is widely used as magnetic storage media in audio and video recording (Tsakalakos 2003), magneto-optical devices (Goya et al., 2003; Kawanishi et al., 1997), magnetic refrigeration (Mcmichael et al., 1992) whereas $\alpha-\mathrm{Fe}_{2} \mathrm{O}_{3}$ in nano-size is a potential candidate for photo anode for possible photo-electrochemical cells (Prosini et al.2002; Wang et al., 2004a). Fe-based nano compounds as positive cathode materials for Li-ion secondary batteries are of interest due to the low-cost and non-toxicity (Lindgren et al., 2002; Wang et al., 2004b; Liu et al., 2009). Cheng et al. (2006) prepared a nano-sized iron oxy-hydroxide (FeOOH) via a hydrolyzing route under mild and facile synthesis condition which delivered a capacity of about $237 \mathrm{mAh} / \mathrm{g}$ in the voltage range from $1.5 \mathrm{~V}$ to $4.2 \mathrm{~V}$, and showed a very good cycling performance in the voltage range from $1.6 \mathrm{~V}$ to $3.3 \mathrm{~V}$ with a capacity of $170 \mathrm{mAh} / \mathrm{g}$. A novel "sacrificial template-accelerated hydrolysis" (STAH) approach to the synthesis of iron oxide-based nanotube arrays including hematite octahedral- $\mathrm{Fe}_{2} \mathrm{O}_{3}$ and magnetite $\mathrm{Fe}_{3} \mathrm{O}_{4}$ was reported by Liu et al. (2010). By introducing glucose into the precursor solution, they obtained carbon/hematite $\left(\mathrm{C} / \alpha-\mathrm{Fe}_{2} \mathrm{O}_{3}\right)$ composite nanotube arrays on large-area flexible alloy substrate, with a large number of pores and uniform carbon distribution at a nanoscale in the nanotube walls. These arrays have been demonstrated as excellent additive-free anode materials for lithium ion batteries in terms of good cycling performance up to 150 times $\left(659 \mathrm{~mA} \mathrm{~h} \mathrm{~g}^{-1}\right)$ and outstanding rate capability.

\subsection{Biological applications}

Biomedical applications of iron based magnetic nanoparticles (MNPs) are classified according to their application inside (in vivo) or outside (in vitro) the body. In vivo applications could be further separated in therapeutic (hyperthermia and drugtargeting) and diagnostic applications (nuclear magnetic resonance (NMR) imaging), while for in vitro applications the main use is in diagnostic (separation/selection and magneto-relaxometry). Aqueous magnetic fluids composed of small magnetic particles about 5-20 nm covered with biocompatible functionalized shells are well known for their use in hyperthermia, as immuno assays, as imaging for the magnetic mapping of organs, as magnetic carriers for identification and isolation of blood cells and antibodies and for transportation of drugs to the places of diseases (Reimer and Weissleder, 1996; Bonnemain, 1998; Rogers et al.,1999; Babincova et al., 2001; Portet et al., 2001; Wang et al., 2001; Wunderbaldinger et al., 2002; Arbab et al., 2003; Pankhurst et al., 2003). Every application needs its own tailored magnetic core/shell composition. Magnetite, $\mathrm{Fe}_{3} \mathrm{O}_{4}$, has a cubic inverse spinel structure where electrons can hop between $\mathrm{Fe}^{2+}$ and $\mathrm{Fe}^{3+}$ ions in the octahedral sites at room temperature, rendering it an important class of half-metallic materials. With proper surface coating, these magnetic nanoparticles can be dispersed into suitable solvents, forming homogeneous suspensions, called ferrofluids (Babincova et al., 2001). Such a suspension can interact with an external magnetic field and be positioned to a specific area, facilitating magnetic resonance imaging for medical diagnosis and $\mathrm{AC}$ magnetic field-assisted cancer therapy. Again the nano size of magnetic particle with large surface area change some of the magnetic properties and exhibit superparamagnetic phenomena and quantum tunneling of magnetization which offer a high potential for several biomedical applications (Reimer and Weissleder, 1996; Bonnemain, 1998; Arbab et al., 2003; Pankhurst et al., 2003). Several iron oxide based cell labeling techniques have been developed including conjugation with antigen-specific internalizing monoclonal antibody, modification of USPIO (ultra small super paramagnetic iron oxide) or MION (mono crystalline iron oxide nanoparticles) with tat-proteins facilitating the incorporation into the cells (Häfeli et al., 1997; Josephson et al., 1999; Lewin et al., 2000; Bulte et al., 2001).

Active research work is continuing in finding suitable biomedical applications of versatile iron oxides in the nano scale both for drug release and drug delivery (Kubo et al., 2001; Frank et al., 2003; Gonzales et al., 2005; Cengelli et al., 2006; Aslam et al., 2007; Naka et al., 2008; Piao et al., 2008; Guo et al., 2009; Mahmoudi et al., 2009; Zheng et al., 2009; Tran et al., 2010). Engineered fluorescent SPIONs have been developed by Cengellie et al. (2006) for drug delivery and imaging of brain-derived structures. These SPIONs were coated with PVA functionalized with a fluorescent reporter molecule and were administered to a microglial cell culture containing immune cells of the nervous system. Mahmoudi et al. (2009) prepared iron oxide NPs with a cross-linked poly (ethylene glycol)-co-fumarate (PEGF) coating. The cross-linked PEGF coating reduced the burst release by $21 \%$ in comparison with the noncross-linked tamoxifen loaded particles. Mono-disperse SPIONs with a mesoporous structure were prepared via simple solvothermal method by Guo et al. (2009) for studying loading and release behaviour of anticancer drug, (Doxorubicin, Dox). The release behaviour of Dox indicated that these SPIONs had a high drug loading capacity and favourable 
release kinetics for this drug. Similar studies have been carried out for targeted delivery applications (Kubo et al., 2001; Gonzales et al., 2005). Most of polymeric coatings in SPIONs are selected from hydrogel categories. Permeability, temperature sensitivity, $\mathrm{pH}$ sensitivity, osmolarity sensitivity, surface functionality, swelling, biodegradability, and surface biorecognition sites are recognized as major factors for controlled drug release applications of hydrogels (Meyers et al., 1963).

Naka et al. (2008) have reported the synthesis of methylimidazolium cation-modified iron oxide nanoparticles and estimated their potential biological application. The modified iron oxide nanoparticles of 7.6 to $11.3 \mathrm{~nm}$ were well-dispersed in water. The iron oxide nanoparticles modified with N-methylimidazolium cation can turn their water-miscibility and binding capacity for DNA by exchanging the counter anions by MRI. Aslam et al. (2007) demonstrated a simple one-step process for the synthesis of iron oxide nanoparticle aqueous colloids using the multifunctional molecule dodecylamine (DDA), which electrostatically complexes with aqueous iron ions (one precursor $\mathrm{Fe}^{2+}$ from $\mathrm{FeCl}_{2}$ ), reduces them, and subsequently caps the nanoparticles. The iron oxide particles thus synthesized were of the face-centred cubic (FCC) phase with a high degree of monodispersity and an appropriate concentration of the amine-capping molecular layer. The magnetic nanocrystalline particles obtained were of average diameter 30 $\pm 10.5 \mathrm{~nm}$ size and were tested for potential application in magnetic resonance imaging (MRI). Piao et al. (2008) reported a novel wrap-bake-peel process, which involves silica coating, heat treatment and finally the removal of the silica layer, to transform the phases and structures of nanostructured materials while preserving their nanostructural characteristics. They described the fabrication of water-dispersible and biocompatible hollow iron oxide nanocapsules by applying this wrap-bake-peel process to spindle-shaped akaganeite $(\beta-\mathrm{FeOOH})$ nanoparticles. Depending on the heat treatment conditions, hollow nanocapsules of either haematite or magnetite were produced. The synthesized water-dispersible magnetite nanocapsules were successfully used as a drug-delivery vehicle, and also as a $T_{2}$ magnetic resonance imaging contrast agent. Doxorubicin (DOX), a chemotherapeutic agent, was used as a model drug and was incorporated into the nanocapsules.

Modified magnetic starch nanoparticles (FA-StNP@ $\mathrm{Fe}_{2} \mathrm{O}_{3}$ ) were synthesized by conjugating folic acid (FA-PEG-NH ${ }_{2}$ ) onto the surface of magnetic starch nanoparticles ( $\mathrm{StNP} @ \mathrm{Fe}_{2} \mathrm{O}_{3}$ ) prepared by reverse microemulsion method (Zheng et al., 2009). The average size of its well dispersed particles was $250 \mathrm{~nm}$. Placing FA-StNP@ $\mathrm{Fe}_{2} \mathrm{O}_{3}$ nanoparticles in the alternating magnetic field for $30 \mathrm{~min}$ resulted in an increase in the suspension temperature from ambient temperature $\left(37^{\circ} \mathrm{C}\right)$ to a value between $42^{\circ} \mathrm{C}$ and $43^{0} \mathrm{C}$.

Magnetic nanoparticles (Tran et al., 2010) have recently been used to treat bone diseases (such as osteoporosis and infection) by using surface modified magnetic nanoparticles. Magnetite $\left(\mathrm{Fe}_{3} \mathrm{O}_{4}\right)$ and maghemite $\left(\mathrm{Fe}_{2} \mathrm{O}_{3}\right)$ were coated with calcium phosphate $(\mathrm{CaP})$.

Various applications of iron oxides/hydroxides/oxyhydroxides in nano form can be attributed to the difference in behaviour of particles in nano scale as compared to their bulk counterparts. The nano particles usually have much larger surface area due to their smaller size and can reduce the volume required to achieve same effect when used as a catalyst. In case of mitigation of anions /cations from aqueous solutions, iron oxides in nano form will have higher number of active sites for adsorption, thereby reducing the amount required per liter of solution. The adsorption process involves surface hydroxyl group interaction with adsorbents. Nano iron oxides exhibit very different magnetic properties which can be used for soft ferrites and biomedical applications including drug delivery and magnetic resonance imaging. Down to the nanoscale, superparamagnetic iron oxide nanoparticles can only be magnetized in the presence of an external magnetic field, which makes them capable of forming stable colloids in a physio-biological medium. Their superparamagnetic property, together with other intrinsic properties, such as low cytotoxicity, colloidal stability, and bioactive molecule conjugation capability, makes such nanomagnets ideal in both in-vitro and in-vivo biomedical applications (Lin et al.,2010).

Considering numerous applications of iron oxides in various emerging fields, tremendous efforts on synthesis of nano-dispersed particles are continuing. The biggest challenge in this field is to economically produce iron oxide nano particles of desired characteristics for specific application in large scale. There has been a lot of progress in understanding the basic science of nano iron oxides but evaluation of economic viability for commercial application needs much more attention.

\section{Conclusions}

1. Iron oxide nano-particles (NPs ) are of considerable interest due to their wide range of applications in fields such as magnetic storage, medicine, chemical industries and water purification.

2. Typical nano-particle synthesis methodologies involve routes including precipitation, sol-gel, hydrothermal, dry vapor deposition, surfactant mediation, microemulsion, electro-deposition and sonochemical.

3. The above mentioned synthetic methods have several advantages and disadvantages for preparing iron oxide nano particles (NPs). While these methods often furnish particles with narrow size distributions they tend to require re-optimization for each desired particle size, shape, or surface functional groups.

4. In terms of size and morphology control of the iron oxide NPs, thermal decomposition and hydrothermal synthetic route seems the optimal methods. For obtaining the water-soluble and biocompatible iron oxide NPs, co-precipitation was often employed, but this method presents low control of the particle shape, broad distributions of sizes and aggregation of particles. As a time competitive alternative, sonochemical route can also be used to synthesis iron oxide NPs with unusual magnetic properties. 
138 Mohapatra and Anand / International Journal of Engineering, Science and Technology, Vol. 2, No. 8, 2010, pp. 127-146

5. The magnetic nano-crystals are receiving much attention as these are now emerging in biomedical applications with new possibilities.

\section{Acknowledgements}

The authors are thankful to Director, Prof. B.K.Mishra, Institute of Minerals and Materials Technology, Bhubaneswar, for his kind permission to publish this paper. They wish to thank Dr. R. K. Paramguru, Head, Hydrometallurgy Department.

\section{References}

Abolanle S. A., Bolade O. A., Jeseelan P., Kenneth I.O., 2010. Electrocatalytic detection of dopamine at single-walled carbon nanotubes-iron(III) oxide nanoparticles platform. Sensor Actuat. B-Chem. Vol.148, pp. 93-102

$\mathrm{Abu}$ Mukh-Qasem R., and Gedanken A., 2005. Sonochemical synthesis of stable hydrosol of $\mathrm{Fe}_{3} \mathrm{O}_{4}$ nanoparticles. J. Colloid Interf. Sci. Vol. 284, No. 2, pp. 489-494.

Alexandrescu R., Morjan I., Voicu I., Dumitrache F., Albu L., Soare I., and Prodan, G., 2005. Combining resonant/non-resonant processes: Nanometer-scale iron-based material preparation via $\mathrm{CO}_{2}$ laser pyrolysis. Appl. Surf. Sci., Vol. 248, No. 1-4, pp. 138146.

Allen M., Willits D., Young M., and Douglas T., 2003. Constrained synthesis of cobalt oxide nano-materials in the 12- subunit protein cage from listeria innocua. Inorg. Chem. Vol. 42, pp. 6300-6305.

Alvarez G.S. Muhammed M., and Zagorodni A.A., 2006. Novel flow injection synthesis of iron oxide nanoparticles with narrow size distribution. Chem. Eng. Sci. Vol. 61, pp. 4625-4633.

Apostolescu N., Geiger B., Hizbullah K., Jan M.T., Kureti S., Reichert D., Schott F., and Weisweiler W., 2001. Selective catalytic reduction of nitrogen oxides by ammonia on iron oxide catalysts. Appl. Catal. B: Environ. Vol. 62, No.1-2, pp. 104-114

Arbab A.S., Bashaw L.A., Miller B.R., Jordan E.K., Lewis B.K., Kalish H., and Frank J.A., 2003. Synthesis of complexable fluorescent superparamagnetic iron oxide nanoparticles (FL SPIONS) and its cell labeling for clinical application. Radiology, Vol. 229, pp. 838-846.

Aslam M., Schultz Elise A., Sun Tao, Meade Thomas, Dravid Vinayak P., 2007. Synthesis of amine-stabilized aqueous colloidal iron oxide nanoparticles. Cryst. Growth \& Design Vol. 7, No. 3, pp. 471-475.

Axel Nørlund Christensena, Torben R. Jensenb, Christian R.H., and Bahlc Elaine DiMasi, 2007. Nano size crystals of goethite, a-FeOOH: Synthesis and thermal transformation. J. Solid State Chem. Vol.180, pp.1431-1435

Babes L., Denizot B., Tanguy G., Le Jeune, J. J., and Jallet P., 1999. Synthesis of iron oxide nanoparticles used as MRI contrast agents: A parametric study. J. Colloid Interf. Sci. Vol. 212, No.2, pp.474-482.

Babincova M., Babinec P., and Bergmann C., 2001. High-gradient magnetic capture of ferrofluids: implications for drug targeting and tumor embolization. Z Naturforsch (Sect C), Vol. 56, pp. 909-911.

Baker A.S.J., Brown A.S.C., Edwards M.A., Hargreaves J.S.J., Kiely C.J., Meagher A., and Pankhurst Q.A., 2000. A structural study of hematite samples prepared from sulfated goethite precursors: the generation of axial mesoporous voids. J. Mater. Chem. Vol.10, pp. 761-766.

Baldrian P., Merhautová V., Gabriel J., Nerud F., Stopka P., Hrubý M., and Beneš M. J., 2006. Decolorization of synthetic dyes by hydrogen peroxide with heterogeneous catalysis by mixed iron oxides. Appl. Catal. B: Environ. Vol.66, No.3-4, 258-264.

Bang J.H., and Suslick K.S., 2007. Sonochemical synthesis of nanosized hollow hematite. J. Am. Chem. Soc., Vol. 129, pp. 22422243.

Barrow N.J., Gerth J., and Brümmer G.W., 1989. Adsorption and diffusion of metals. J. Soil Sci. Vol. 40, pp. 437-450.

Bee A., Massart R., and Neveu S., 1995. Synthesis of very fine maghemite particles. J. Magn. Magn. Mater. Vol. 149, No. 1-2, pp. 6-9.

Benjamin M. M., Leckie J.O., 1981. Multiple-site adsorption of $\mathrm{Cd}, \mathrm{Cu}, \mathrm{Zn}$ and $\mathrm{Pb}$ on amorphous iron oxyhydroxide. J. Colloid Interf. Sci. Vol. 79, pp. 209.

Blesa M. A., and Matijevic E., 1989. Phase transformation of iron oxides, oxyhydroxides, and hydrous oxides in aqueous media. Adv. Colloid Interf. Sci. Vol. 29, pp. 173-221.

Bonnemain B., 1998. Superparamagnetic agents in magnetic resonance imaging: Physicochemical characteristics and clinical applications - a review. J. Drug Target Vol. 6, pp. 167-174.

Bruchez Jr. M., Moronne M., Gin P., Weiss S., and Alivisatos A.P.,1998. Semiconductor nanocrystals as fluorescent biological labels. Science Vol. 281, pp. 2013-2016.

Bulte J.W., Douglas T., Witwer B., Zhang S.C., Strable E., Lewis B.K., Zywicke H., Miller B., van Gelderen P., Moskowitz B.M., Duncan I.D. J, and Frank. A., 2001. Magnetodendrimers allow endosomal magnetic labeling and in vivo tracking of stem cells, Nat. Biotechnol. Vol. 19, pp.1141-1147. 
Butter K., Kassapidou K., Vroege G.J., and Philipse A.P., 2005. Preparation and properties of colloidal iron dispersions. J. Colloid Interf. Sci. Vol.287, No. 2, pp. 485-495.

Cabuil V., Dubois E., Neveau S., Bacri J. C., Hasmonay E., and Perzynski R. 1995. Phase separation in aqueous magnetic colloidal solutions. Prog. Colloid Polym. Sci., 98, 23-29.

Catlow C. R., Corish J., Hennesy J., Mackrod W. C., 1988. Theoretical calculation of the textures and ion transport in alpha$\mathrm{Fe}_{2} \mathrm{O}_{3}$ and alpha-Cr $\mathrm{O}_{3}$. J. Am. Ceram. Soc., Vol.71, pp. $42-49$.

Cannas C., Gatteschi D., Musinu A., Piccaluga G., and Sangregorio C., 1998. Structural and magnetic properties of $\mathrm{Fe}_{2} \mathrm{O}_{3}$ nanoparticles dispersed over a silica matrix. J. Phys. Chem., Vol. 102, pp.7721-7726.

Cengelli F., Maysinger D., Tschudi-Monnet F., Montet X., Corot C., Petri-Fink A., Hofmann H., and Juillerat-Jeanneret L., 2006. Interaction of functionalized superparamagnetic iron oxide nanoparticles with brain structures. J. Pharma. Exp. Ther. Vol. 318 No.1, pp.108-116.

Chan W.C., and Nie S., 1998. Quantum dot bioconjugates for ultrasensitive non isotopic detection. Science Vol.281, pp. 20162018.

Chen, D., and Xu, R. 1998, Iron oxide synthesis using a continuous hydrothermal and solvothermal system. Mater. Res. Bull. Vol. 33, pp. 1015-1021.

Cheng Liang , Li Hui-qiao, and Xia Yong-yao., 2006. A hybrid nonaqueous electrochemical super capacitor using nano-sized iron oxyhydroxide and activated carbon. J. Solid State Electr. Vol. 10, pp. 405-410.

Choo K.H., and Kang S.-K., 2003. Removal of residual organic matter from secondary effluent by iron oxides adsorption. Desalination Vol.154, pp.139-146.

Chin A.B., and Yaacob I.I., 2007. Synthesis and characterization of magnetic iron oxide nanoparticles via w/o microemulsion and Massart's procedure. J. Mater. Process. Technol. Vol. 191, pp. 235-237.

Christensen A.N., 1968. Hydrothermal preparation of goethite and hematite from amorphous iron(III) hydroxide. Acta Chem. Scand. Vol. 22, pp. 1487-1490.

Ciesla U., Demuth D., Leon R., Petroff P., Stucky G., Unger K., and Schüth F. 1994. Surfactant controlled preparation of mesostructured transition-metal oxide compounds. J. Chem. Soc. Chem. Commun. pp.1387-1388.

Clausen L., Fabricius I., 2001. Adsorption onto iron oxides. J. Environ. Qual. Vol. 30, pp. 858-869.

Cornell R. M., and Schwertmann U., 1996. The Iron Oxides Structure, Properties, Reactions, Occurrence and Uses. VCH Verlagsgesellschaft Weinheim.

Cornell R. M., and Schwertmann U., 2003. Iron oxides. 2nd Edn., Wiley-VCH Verlagsgesellschaft Weinheim.

Deliyanni E.A., Nalbandian L., and Matis K.A. 2006. Adsorptive removal of arsenites by a nanocrystalline hybrid surfactantakaganeite sorbent. J. Colloid Interf. Sci. Vol. 302, pp.458-466.

Ding M., de Jong B.H.W.S., Roosendaal S.J., Vredenberg A., 2000. XPS studies on the electronic structure of bonding between solid and solutes: adsorption of arsenate, chromate, phosphate, $\mathrm{Pb}^{2+}$, and $\mathrm{Zn}^{2+}$ ions on amorphous black ferric oxyhydroxide. Geochim. Cosmochim. Acta. Vol. 64, No. 7, pp. 1209-1219.

Denizli A., and Say R., 2001. Preparation of magnetic dye affinity adsorbent and its use in the removal of aluminium ions. $J$. Biomater. Sci. Polym. Edn. Vol.12, pp.1059-1073.

Denizot B., Tanguy G., Hindre F., Rump E., Le Jeune, J. J., and Jallet P., 1999. Phosphorylcholine coating of iron oxide nanoparticles. J. Colloid Interf. Sci. Vol. 209, No.1, pp. 66-71.

Dong Y., Yang H., Rao R., and Zhang A. 2009. Selective synthesis of $\alpha-\mathrm{FeOOH}$ and $\alpha-\mathrm{Fe}_{2} \mathrm{O}$ 3 nanorods via a temperature controlled process. J. Nanoscience and Technology Vol. 9, No. 8, pp. 4774-4779.

Domingo C., Rodriguez-Clemente R., and Blesa M.,1994. Morphological properties of $\alpha-\mathrm{FeOOH}, \gamma-\mathrm{FeOOH}$ and $\mathrm{Fe}_{3} \mathrm{O}_{4}$ obtained by oxidation of aqueous Fe(II) solutions. J. Colloid Interf. Sci. Vol.165, pp. 244-252.

Douglas T., and Stark V.T., 2000. Nanophase cobalt oxyhydroxide mineral synthesized within the protein cage. Inorg. Chem. Vol. 39, pp. 1828-1830.

Douglas T., and Young M. 1998. Host-guest encapsulation of materials by assembled virus protein cages. Nature Vol. 393 pp. $152-155$.

Dubertret B., Skourides P., Norris D.J., Noireaux V., Brivanlou A.H., and Libchaber A. 2002. In vivo imaging of quantum dots encapsulated in phospholipid micelles. Science Vol. 298, pp.1759-1762.

Elizabeth P., 1992. Nanotechnology yields transparent magnet-tiny iron oxide particles become more transparent than in bulk form - brief article. Science News July 11.

Ennas G., Musinu A., Piccaluga G., Zedda D., Gatteschi, D., Sangregorio C., Stanger J. L., Concas G., and Spano G., 1998. Characterization of iron-oxide nanoparticles in a $\mathrm{Fe}_{2} \mathrm{O}_{3}-\mathrm{SiO}_{2}$ composite prepared by a Sol-gel method. Chem. Mater. Vol. 10, pp. 495-502.

Fang Xiao-Liang, Li Yue, Chen Cheng, Kuang Qin, Gao Xiang-Zhi, Xie Zhao-Xiong, Xie Su-Yuan, Huang Rong-Bin, and Zheng Lan-Sun. 2010. pH-Induced simultaneous synthesis and self-assembly of 3D layered $\beta$-FeOOH nanorods. Langmuir Vol. 26, No. 4, pp. 2745-2750.

Fauconnier N., Bee A., Roger J., and Pons, J. N. 1996. Adsorption of gluconic and citric acids on maghemite particles in aqueous medium. Prog. Colloid Polym. Sci. Vol. 100, pp. 212-216. 
Fauconnier N., Bee A., Roger J., and Pons, J. N., 1999. Synthesis of aqueous magnetic liquids by surface complexation of maghemite nanoparticles. J. Mol. Liq. Vol. 83, pp. 233-242.

Fauconnier N., Pons J. N., Roger J., and Bee A., 1997. Thiolation of maghemite nanoparticles by dimercaptosuccinic acid. $J$. Colloid Interf. Sci. Vol. 194, No. 2, pp. 427-433.

Frank J.A., Miller B.R., Arbab A.S., Zywicke H.A., Jordan E.K., Lewis B.K., Bryant Jr. L.H., and Bulte J.W., 2003. Clinically applicable labeling of mammalian and stem cells by combining superparamagnetic iron oxides and transfection agents Radiology, Vol. 228, No. 2, pp. 480-487.

Gazeau F., Bacri J.C., Gendron F., Perzynski R., Raikher Yu. L., Stepanov V.I., and Dubois E., 1998. Magnetic resonance of ferrite nanoparticles: evidence of surface effects. J. Magn. Magn. Mater. Vol. 186, pp.175-187.

Ge Song, Shi Xiangyang, Sun Kai, Li Changpeng, Uher Ctirad, Baker Jr. James R., Mark M., Banaszak Holl, and Bradford G. Orr, 2009. Facile hydrothermal synthesis of iron oxide nanoparticles with tunable magnetic properties J. Phys. Chem. C, Vol. 113, pp. 13593-13599

Geng Fengxia, Zhao Zhigang, Cong Hongtao, Geng Jianxin, and Cheng Hui-Ming, 2006. An environment-friendly microemulsion approach to $\alpha-\mathrm{FeOOH}$ nanorods at room temperature. Materials Research Bulletin Vol. 41, No. 12, pp. 2238-2243.

Goya G.F., Berquo T.S., Fonseca F.C., and Morales M.P., 2003. Static and dynamic magnetic properties of spherical magnetite nanoparticles, J. Appl. Phys. Vol. 94, pp. 3520-3528.

Gonzales M., and Krishnan K.M., 2005. Synthesis of magnetoliposomes with monodisperse iron oxide nanocrystal cores for hyperthermia. J. Magn.Magn. Mater. Vol. 293, pp.265-270.

Gref R., Minamitake Y., Peracchia M.T., Trubetskoy V., Torchilin V., and Langer R. 1994. Biodegradable long-circulating polymeric nanospheres. Science Vol. 263, pp.16.

Guo S., Li D., Zhang L., Li J., and Wang E., 2009. Monodisperse mesoporous super-paramagnetic single-crystal magnetite nanoparticles for drug delivery. Biomaterials Vol. 30, No.10, pp.1881-1889.

Gupta A.K., and Wells S., 2004. Surface-modified superparamagnetic nanoparticles for drug delivery: Preparation, characterization, and cytotoxicity studies. IEEE Trans. Nanobiosci. Vol. 3, pp. 66-73.

Häfeli U., Schütt W., Teller J., and Zborowski M. (Ed.), Scientific and Clinical Applications of Magnetic Carriers. Plenum Press, New York (1997).

Hiemstra T., Rahnemaie R., and Riemsdijk W.H.V., 2004. Surface complexation of carbonate on goethite: IR spectroscopy, structure and charge distribution. J. Colloid Interf. Sci. Vol. 278, No. 2, pp. 282-290.

Hutchings G.J., Hall M.S., Carley A.F., Landon P., Solsona B.E., Kiely C.J., Herzing A., Makkee M., Moulijn J.A., and Overweg A., 2006. Role of gold cations in the oxidation of carbon monoxide catalyzed by iron oxide-supported gold. J. Catalysis Vol. 242, No.1, pp. 71-81.

Hyeon T., Seong Lee S., Park J., Chung Y., and Na H.B., 2001. Synthesis of highly crystalline and monodisperse maghemite nanocrystallites without a size-selection process. J. Am. Chem. Soc. Vol. 123, pp. 12798-12801.

Iijima M., Yonemochi Y., Tsukada M., and Kamiya H., 2006. Microstructure control of iron hydroxide nanoparticles using surfactants with different molecular structures. J. Colloid Interf. Sci., Vol. 298, No.1, pp. 202-208.

Itoh H., and Sugimoto T., 2003. Systematic control of size, shape, structure, and magnetic properties of uniform magnetite and maghemite particles. J. Colloid Interf. Sci. Vol. 265, No.2, pp. 283-295.

Jana N.R., Chen Y., and Peng X., 2004. Size- and shape-controlled magnetic (Cr, Mn, Fe, Co, Ni) oxide nanocrystals via a simple and general approach. Chem. Mater. Vol. 16, pp. 3931-3935.

Jiang W.,Yang H.-C., Yang S.Y., Horng H.E., Hung J.C., Chen Y.C., and Hong C-Y., 2004. Preparation and properties of superparamagnetic nanoparticles with narrow size distribution and biocompatible. J. Magn. Magn. Mater. Vol. 283, pp. 210-214.

Jing Z., and Wu S., 2004. Synthesis, characterization and magnetic properties of $\gamma-\mathrm{Fe}_{2} \mathrm{O}_{3}$ nanoparticles via a non-aqueous medium. J. Solid State Chem. Vol. 177, pp. 1213-1218.

Jolivet, J P. De la Solution a ' l'Oxyde; Inter Editions et CNRS Editions: Paris, France, 1994.

Jolivet, J. P. Metal Oxide Chemistry and Synthesis. From Solution to Solid State; Wiley: Chichester, U.K., 2000.

Jolivet J. P., Belleville P., Tronc E., and Livage J., 1992. Influence of Fe (II) on the formation of the spinel iron oxide in alkaline medium. Clays Clay Miner. Vol. 40, pp. 531-539.

Josephson L., Tung C.H., Moore A., and Weissleder R. 1999. High-efficiency intracellular magnetic labeling with novel superparamagnetic -Tat peptide conjugates. Bioconjug. Chem. Vol. 10, pp.186-191.

Julian-Lopez B., Boissie’re C., Chane'ac C., Grosso D., Vasseur S., Miraux S., Duguet E., and Sanchez C., 2007. Mesoporous maghemite-organosilica microspheres: a promising route towards multifunctional platforms for smart diagnosis and therapy $J$. Mater. Chem. Vol. 17, pp. 1563-1569.

Jun Y.W., Huh Y.M., Choi J.S., Lee J.H., Song H.T., Kim S., Yoon S., Kim K.S., Shin J.S., Suh J.S., and Cheon J., 2005. Nanoscale size effect of magnetic nanocrystals and their utilization for cancer diagnosis via magnetic resonance imaging. $J . A m$. Chem. Soc. Vol. 127, pp. 5732-5733.

Jungk H.O., and Feldmann C., 2000. Non-agglomerated, sub-micron - $\mathrm{Fe}_{2} \mathrm{O}_{3}$ particles: Preparation and application. J. Mater. Res. Vol. 5, pp. 2244-2248. 
Kahn, H.R., and Petrikowski K., 2000. Anisotropic structural and magnetic properties of arrays of $\mathrm{Fe}_{26} \mathrm{Ni}_{74}$ nanowires electrodeposited in the pores of anodic alumina. J. Magn. Magn. Mater. Vol. 526, pp. 215-216.

Kanai H., Mizutani H., Tanaka T., Funabiki T., Yoshida S., and Takano M., 1992. Fourier transforms for k3-weighted Fe-K edge EXAFS spectra of ct- $\mathrm{Fe}_{2} \mathrm{O}_{3}$ (a), and $\mathrm{Fe}, \mathrm{MnSO}_{4} 2 " / \mathrm{ZrO}_{2}$. J. Mater. Chem. Vol. 2, pp. 703-707.

Kaushik A., Khan R., Solanki P.R., Pandey P., Alam J., Ahmad S., and Malhotra, B.D., 2008. Iron oxide nanoparticleschitosan composite based glucose biosensor. Biosens. Bioelectron. Vol. 24, pp. 676-683.

Kaushik A., Khan R., Solanki P.R., Pandey P., Alam J., Ahmad S., and Malhotra B.D., 2009. Iron oxide-chitosan nanobiocomposite for urea sensor. Sensor Actuat. B-Chem. Vol.138, No. 2, pp. 572-580.

Kawanishi Y., Tamaki T., Sakuragi M., 1997. Adsorption of silver colloidal particles through covalent linkage to self-assembled monolayers. Langmuir Vol. 13, pp. 5244-5248.

Khatun S., Mohapatra M., and Anand S., 2007. Synthetic goethite - A scavenger for $\mathrm{Pb}(\mathrm{II})$. In proceeding of "International Seminar in Mineral Processing Technology, (MPT-2007)" held at IIT, Mumbai during $27^{\text {th }}-29^{\text {th }}$ Feb., 2007 Editors: N.K.Khosla and G.N.Jadav, pp 733-737.

Kim E. H., Lee H.S., Kwak B.K., and Kim B.K., 2005. Synthesis of ferrofluid with magnetic nanoparticles by sonochemical method for MRI contrast agent. J. Magn. Magn. Mater. Vol. 289, pp. 328-330.

Kim D.K., Zhang Y., Voit W., Rao K.V., and Muhammed, M., 2001.Characterization and MRI study of surfactant-coated superparamagnetic nanoparticles administered into the rat brain. J. Magn. Magn. Mater. Vol. 225, pp. 30-36.

Klem M.T., Willits D., Young M., and Douglas T., 2003. 2-D array formation of genetically engineered viral cages on Au surfaces and imaging by atomic force microscopy. J. Am. Chem. Soc. Vol. 125, pp. 10806-10807.

Kubo T., Sugita T., Shimose S., Nitta Y., Ikuta Y., and Murakami T., 2001. Targeted systemic chemotherapy using magnetic liposomes with incorporated adriamycin for osteosarcoma in hamsters. Int. J. Oncology Vol.18, No. 1, pp. 121-125.

Kumar R.V., Koltypin Y., Xu X. N., Yeshurun Y., Gedanken A., and Felner I., 2001. Fabrication of magnetite nanorods by ultrasound irradiation. J. App. Phy. Vol. 89, No. 11, pp. 6324-6328.

LaMer V.K., and Dinegar R.H., 1950. Theory, production and mechanism of formation of monodispersed hydrosols. J. Am. Chem. Soc. Vol.72, pp. 4847-4854.

Lee Duk-Dong, and Choi Dong-Han, 1990.Thick-film hydrocarbon gas sensors. Sensor Actuat. B-Chem. Vol.1, No. 1-6, pp. 231235.

Lee S.J., Jeong J.R., Shin S.C., Huh Y.M., Song H.T., Suh J.S., Chang Y.H., Jeon B.S., and Kim J.D., 2005a. Intracellular translocation of superparamagnetic iron oxide nanoparticles encapsulated with peptide-conjugated poly(D,L lactide-coglycolide). J. Appl. Phys. Vol. 97, pp. 10Q913-10Q913-3.

Lee Y., Lee J., Bae C.J., Park J.G., Noh H.J., Park J.H., and Hyeon T., 2005b. Large-scale synthesis of uniform and crystalline magnetite nanoparticles using reverse micelles as nanoreactors under reflux conditions. Adv. Funct. Mater. Vol.15, No. 3, pp. 503-509.

Lewin M., Carlesso N., Tung C.H., Tang X.W., Cory D., Scadden D.T., and Weissleder R., 2000. Tat peptide-derivatized magnetic nanoparticles allow in vivo tracking and recovery of progenitor cells. Nat. Biotechnol. Vol. 18, pp. $410-414$.

Li P., Miser D., Rabiei S., Yadav R., and Hajaligol M.R., 2003.The removal of carbon monoxide by iron oxide nanoparticles. Appl. Catal. B: Environ. Vol. 43, pp. 151-162.

Li P., Shin E.J., Miser D., Hajaligol M.R., Rasouli F., 2004. B. Eds. Zhou, S. Hermans and G.A. Somorjai, In: Nanotechnology in Catalysis Kluwer Academic/Plenu, New York, pp.515.

Li Y., Liao H., Y. Qian, 1998. Hydrothermal synthesis of ultrafine $\alpha-\mathrm{Fe}_{2} \mathrm{O}_{3}$ and $\mathrm{Fe}_{3} \mathrm{O}_{4}$ powders. Mat. Res. Bull. Vol. 33, pp. 841844.

Li Z., Choi C.J., You J.H., Kim B., and Zhang Z.D., 2004a. Nanocrystalline $\alpha$-Fe and $\varepsilon-\mathrm{Fe}_{3} \mathrm{~N}$ particles prepared by chemical vapor condensation process. J. Magn. Magn. Mater. Vol. 283, pp. 8-15.

Li Z., Chen H., Bao H.B., and Gao, M.Y., 2004b. One-pot reaction to synthesize water- soluble magnetite nanocrystals. Chem. Mater. Vol.16, pp.1391-1393.

Li Z., Sun Q., and Gao M., 2005a. Preparation of water-soluble magnetite nanocrystals from hydrated ferric salts in 2-Pyrrolidone: Mechanism leading to $\mathrm{Fe}_{3} \mathrm{O}_{4}$. Angew. Chem. Int. Ed. Vol. 44, No.1, pp. 123-126.

Li Z., Wei L., Gao M., and Lei H., 2005b. One-pot reaction to synthesize bio- compatible magnetite nanoparticles. Adv. Mater. Vol. 8, pp. 1001-1005.

Li Z., Chen H., Bao H., and Gao M., 2004c. One-pot reaction to synthesize water-soluble magnetite nanocrystals. Chem. Mater. Vol. 16, pp. 1391-1393.

Liang M-T., Wang S-H., Chang Y-L., Hsiang H-I., Huang H-J., Tsai M-H., Juan W-C., Lu S-F., 2010. Iron oxide synthesis using a continuous hydrothermal and solvothermal system. Ceram. Int. Vol. 36, No. 3, pp. 1131-1135.

Lim I.S., Jang G.E., Kim C.K., and Yoon D.H., 2001. Fabrication and gas sensing characteristics of pure and Pt-doped $\gamma$-Fe $\mathrm{F}_{2} \mathrm{O}_{3}$ thin film. Sensor Actuat. B-Chem.Vol. 77, No.1-2, pp. 215-220.

Lima M.D., Bonadiman R., Andrade M.J.de, Toniolo J., and Bergmann C.P., 2006. Synthesis of multi-walled carbon nanotubes by catalytic chemical vapor deposition using $\mathrm{Cr}_{2-x} \mathrm{Fe}_{x} \mathrm{O}_{3}$ as catalyst. Diamond and Related Material Vol.15, pp.1708-1713. 
Lin M.M, Kim, H., and Mohammad M., 2010. Iron oxide -based nanomagnets in nano medicine: Fabrication and applications. Nano Reviews Vol. 1, pp. 1-17.

Lindgren T., Wang H., Beermann N., Vayssieres L., Hagfeldt A., and Lindquist S., 2002. Aqueous photoelectrochemistry of hematite nanorod array. Sol. Energ. Mat. Sol. C Vol. 71, No.2, pp. 231-243.

Liu Hao, Wexler David, and Wang Guoxiu, 2009. One-pot facile synthesis of iron oxide nanowires as high capacity anode materials for lithium ion batteries. J. Alloys and Compounds Vol. 487, No. (1-2), pp. L24-L27.

Liu Jinping, Li Yuanyuan, Fan Hongin, Zhu Zhihong, Jiang Jian, Ding Ruimin, Hu Yingying, and Huang Xintang, 2010. Iron oxide-based nanotube arrays derived from sacrificial template-accelerated hydrolysis: Large-area design and reversible lithium storage. Chem. Mater. Vol. 22, pp. 212-217.

Liu Lu, Kou Hui-Zhong, Mo Wenling, Liu Huajie, and Wang Yuqiu, 2006. Surfactant-assisted synthesis of $\gamma-\mathrm{Fe}_{2} \mathrm{O}_{3}$ nanotubes and nanorods with shape-dependent magnetic properties. J. Phys. Chem. B Vol. 110, pp.15218-15223

Livage J., M Henry., and Sanchez C., 1988. Sol-gel chemistry of transition metal oxides. Prog. Solid State Chem. Vol.18, pp. 259341.

Luengo C., Brigante M., Antelo J., and Avena M., 2006. Kinetics of phosphate adsorption on goethite: Comparing batch adsorption and ATR-IR measurements. J. Colloid Interf. Sci. Vol. 300, No. 2, pp. 511-518.

Mahmoudi M., Simchi A., Imani M., Hafeli U.O., 2009. Superparamagnetic iron oxide nanoparticles with rigid cross-linked polyethylene glycol fumarate coating for application in imaging and drug delivery. J. Phy. Chem. C Vol. 113, No. 19, pp. 81248131.

Manceau A., Schlegel M.L., Musso M., Sole V.A., Gauthi C., Petit P.E., and Trolard F., 2000. Crystal chemistry of trace elements in natural and synthetic goethite. Geochim. Cosmochim. Acta. Vol. 64, pp. 3643-3661

Massart R., 1981. Preparation of aqueous magnetic liquids in alkaline and acidic media. IEEE Trans. Magn. Vol.17, 1247-1248.

Massart R., and Cabuil V., 1987. Synthèse en milieu alcalin de magnétite colloïdale: contrôle du rendement et de la taille des particules. J. Chim. Phys., Vol. 84, pp. 961-973.

Massart R., Dubois E., Cabuil V., Hasmonay E., 1995. Preparation and properties of monodisperse magnetic fluids. J. Magn. Magn.Mater. Vol. 149, No. 1-2. pp. 1-5.

Mcmichael R.D., Shull R.D., and Swartzendruber L.J., 1992. Magnetocaloric effect in superparamagnets. J. Magn. Magn. Mater. Vol. 111, No. 1-2, pp. 29-33.

Miyata, T., Ishino, Y., and Hirashima T., 1978. Catalytic reduction of aromatic nitro compounds with hydrazine hydrate in the presence of iron(III) oxide hydroxide. Synthesis pp. 834-835.

Mizutani Naoya, Iwasaki, Satoru Watano, Takeshi Yanagida, and Tomoji Kawa, 2010. Size control of magnetite nanoparticles in Tomohiro hydrothermal synthesis by coexistence of lactate and sulfate ions. Current App. Phy. Vol. 10, pp. 801-806

Mohapatra M., Anand S., Das R. P., Upadhyay C., and Verma H. C., 2003. Effect of addition of Cu(II), Ni(II) and Co(II) ions on conversion of crystalline goethite to magnetite in $\mathrm{NH}_{3}-\mathrm{FeSO}_{4}-\mathrm{H}_{2} \mathrm{O}$ medium. Int. J. Miner. Process. Vol. 69, pp. 75-86.

Mohapatra M., Upadhyay C., Anand S., Verma H.C., and Das R.P., 2005a. Effect of Ni doping on the properties of fine magnetite particles. J. Magn. Magn. Mater. Vol. 295, pp. 44-50.

Mohapatra M., Sahoo S.K., Mohanty C.K., Das R. P., and Anand S., 2005b. Effect of Ce(IV) doping on formation of goethite and its transformation to hematite. Mater. Chem. Phy. Vol. 94, pp. 417-422.

Mohapatra M., Sahoo S.K., Anand S., and Das R. P., 2006a. Adsorption behaviour of As(V) on Fe(III) oxy hydroxides. J. Colloid Interf. Sci., Vol. 298, pp. 6-12.

Mohapatra M., Sahoo S.K., Anand S., and Das R.P., 2006b. Removal of As(V) by Cu(II)-, Ni(II)-, or Co(II)-doped goethite samples. J. Colloid. Interf. Sci. Vol. 298, No. 6-12.

Mohapatra M., Rout K., and Anand S., 2009. Preparaion, characterization and heavy metal ion adsorption on Mg(II) doped goethite. J. Hazard. Mater. Vol. 171, No.1-3, pp. 417-423

Mohapatra M., Padhi T., Dash T., Singh P., Anand S., and Mishra B.K., 2010a. Facile synthesis of nano structured high surface area 6-line ferrihydrite and its cation sorption behaviour. Communicated to Toxicological \& Environmental Chemistry.

Mohapatra M., Mohapatra L., Anand S., Mishra B. K., 2010b. In-Situ one pot synthesis of high surface area nano akaganeite powder and its cation sorption behaviour. Journal of Chemical Engineering Data Vol. 55, pp. 1486-1491.

Mohapatra M., Rout K., Gupta S., Singh P., Anand S., and Mishra B.K., 2010c. Facile insitu synthesis of goethite in reducing environment and its application for fluoride. Journal of Nano Particle Research Vol. 12, pp. 681-686.

Mohapatra M., Rout K., Singh P., Anand S., Layek S., Verma H.C., and Mishra B.K., 2010d. Fluoride adsorption studies on mixed-phase nano iron oxides prepared by surfactant mediation-precipitation technique communicated to J. Hazar. Mater.

Morales M.P., Bomati-Miguel O., Perez de Alejo R., Ruiz-Cabello J., Veintemillas-Vendaguer S., and Ogrady K., 2003. Contrast agents for MRI based on iron oxide nanoparticles prepared by laser pyrolysis. J. Magn. Magn. Mater. Vol. 266, pp. 102-109.

Naka K., Narita A., Tanaka H., Chujo Y., Morita M., Inubushi T., Nishimura I., Hiruta J., Shibayama H., Koga M., Ishibashi S., Seki J., Kizaka-Kondoh S., and Hiraoka M., 2008. Biomedical applications of imidazolium cation-modified iron oxide nanoparticles. Polym. Adv. Technol. Vol. 19, pp. 1421-1429.

Neri G., Bonavita A., Galvagno S., Siciliano P., and Capone S., 2002. $\mathrm{CO}$ and $\mathrm{NO}_{2}$ sensing properties of doped-Fe $\mathrm{O}_{3}$ thin films prepared by LPD. Sensor Actuat. B-Chem. Vol. 82, No. 1, pp. 40-47 
Neri G., Rizzo G., Galvagno S., Loiacono G., Donato A., Musolino M.G., Pietropaolo R. and Rombi E., 2004. Sol-gel synthesis, characterization and catalytic properties of Fe-Ti mixed oxides. Appl. Catal. A: General Vol. 274, No. 1-2, pp. 243-251.

Pal B., Hata T., Goto K., and Nogami G., 2001. Photocatalytic degradation of $o$-cresol sensitized by iron-titania binary photocatalysts. J. Molecular Catal. A: Chem. Vol.169, No. 1-2, pp. 147-155.

Neri G., Bonavita A., Rizzo G., Galvagno S., Capone S., and Siciliano P., 2006. Methanol gas-sensing properties of $\mathrm{CeO}_{2}-\mathrm{Fe}_{2} \mathrm{O}_{3}$ thin films. Sensor Actuat. B-Chem. Vol. 114, No. 2, pp. 687-695.

Nicola P., Stephanie G., Pablo B., Pierre B., Markus A., and Markus N., 2005, Nanocrystals: Nonaqueous synthesis, characterization, and solubility. Chem. Mater. Vol.17, pp. 3044-3049.

Oscar Bomatí-Miguel, Lena Mazeina, Alexandra Navrotsky, Sabino Veintemillas-Verdaguer, 2008. Calorimetric study of maghemite nanoparticles synthesized by laser-induced pyrolysis. Chem. Mater. Vol. 20, pp. 591-598.

Ozaki M., Kratohvil S., and Matijevic E., 1984. Formation of monodispersed spindle-type hematite particles. J. Colloid Interf. Sci. Vol. 102, No. 1, pp. 146-151.

Ozaki M., and Matijevic E., 1985. Preparation and magnetic properties of monodispersed spindle-type $\gamma-\mathrm{Fe}_{2} \mathrm{O}_{3}$ particles. J. Colloid Interf. Sci. Vol. 107, No.1, pp. 199-203.

Ozaki M., Ookoshi N., Matijevic E., 1990. Preparation and magnetic properties of uniform hematite platelets. J. Colloid Interf. Sci. Vol. 137, No. 2, pp. 546-549.

Pankhurst Q.A., Connolly J., Jones S.K., and Dobson J., 2003. Applications of magnetic nanoparticles in biomedicine. J. Phys. D Appl. Phys. Vol. 36, pp. R167-181.

Park J., An K., Hwang Y., Park J.G., Noh H.J., Kim J.Y., Park J.H., Hwang N.M., and Hyeron J.H. 2004. Ultra-large-scale syntheses of monodisperse nanocrystals. Nat. Mater. Vol. 3, pp. 891-893.

Park J., Lee E., Hwang N.M., Kang M., Kim S.C., Hwang J.G., Park G., Noh H.J., Kim J.H., Park J.H, and Hyeron T., 2005. One-nanometer-scale size-controlled synthesis of monodisperse magnetic iron oxide nanoparticles. Angew.Chem. Int. Ed. Vol. 44, pp. 2872-2877.

Pascal C., Pascal J.L., Favier F., Elidrissi Moubtassim M.L., and Payen C., 1999. Electrochemical synthesis for the control of $\gamma-\mathrm{Fe}_{2} \mathrm{O}_{3}$ nanoparticle size. Morphology, microstructure, and magnetic behavior. Chem. Mater. Vol. 11, pp. 141-147.

Pardoe H., Chua-anusorn W., St. Pierre T.G., and Dobson J., 2001. Structural and magnetic properties of nanoscale iron oxide particles synthesized in the presence of dextran or polyvinyl alcohol. J. Magn.Magn. Mater. Vol. 225, No. 1-2, pp. 41-46.

Peng J., and Chai C.C.,1993. A study of the sensing characteristics of $\mathrm{Fe}_{2} \mathrm{O}_{3}$ gas-sensing thin film. Sensor Actuat. B-Chem. Vol. 14, No. (1-3), pp. 591-593.

Perez-Alonso F.J., Melián-Cabrera I., López Granados M., Kapteijn F., and Fierro J.L.G., 2006. Synergy of $\mathrm{Fe}_{\mathrm{x}} \mathrm{Ce}_{1-\mathrm{x}} \mathrm{O}_{2}$ mixed oxides for $\mathrm{N}_{2} \mathrm{O}$ decomposition. J. Catalysis Vol. 239, pp. 340-346.

Perkas Nina, Koltypin Yuri Palchik, Oleg, Gedanken Aharon, and Chandrasekaran S., 2001. Oxidation of cyclohexane with nanostructured amorphous catalysts under mild conditions. Applied Catalysis A: Vol.209, No.1-2, pp.125-130.

Piao Yuanzhe, Kim Jaeyun, Na Hyon Bin, Kim Dokyoon, Baek Ji Seon, Ko Mi Kyeong, Lee Jung Hee, Shokouhimehr Mohammadreza, and Hyeon Taegwan, 2008. Wrap-bake-peel process for nanostructural transformation from $\gamma$-FeOOH nanorods to biocompatible iron oxide nano capsules. Nature Materials, Vol. 7, pp. 242-247.

Pieters B.R., Williams R.A., Webb C., and 1992. R.A. Williams, Ed., In: Colloid and Surface Engineering Applications in the Process Industries, Butterworth-Heinemann, Oxford, pp. 248.

Pinkas J., Reichlova V., Zboril R., Moravec Z., Bezdicka P., and Matejkova J., 2008. Sonochemical synthesis of amorphous nanoscopic iron(III) oxide from Fe(acac) $)_{3}$. Ultrason. Sonochem. Vol. 15, pp. 257-264.

Portet D., Denizot B., and Rump E., 2001. Nonpolymeric coatings of iron oxide colloids for biological use as magnetic resonance imaging contrast agents. J. Colloid Interf. Sci. Vol. 238, No. 1, pp. 37-42.

Prosini P., Lisi M., Scaccia S., Carewska M., Cardellini F., and Pasquali M., 2002. Synthesis and characterization of amorphous hydrated $\mathrm{FePO}_{4}$ and its electrode performance in lithium batteries. J. Electrochem. Soc. Vol. 149, pp. A297-A301.

Raj K., and Moskovitz R., 1990. Commercial applications of ferrofluids. J. Magn. Magn. Mater. Vol. 85, pp. 233-245.

Randall S.R., Sherman D.M., and Ragnarsdottir K.V., 2001. Sorption of As(V) on green rust $\left(\mathrm{Fe}_{4}(\mathrm{II}) \mathrm{Fe}_{2}(\mathrm{III})(\mathrm{OH})_{12} \mathrm{SO}_{4} .3 \mathrm{H}_{2} \mathrm{O}\right)$ and lepidocrocite $(\gamma-\mathrm{FeOOH})$ : Surface complexes from EXAFS spectroscopy. Geochim. Cosmochim. Acta. Vol. 65, pp. 1015-1023.

Reddy C.V.G., Cao W., Tan O.K., and Zhu W., 2002. Preparation of $\mathrm{Fe}_{2} \mathrm{O}_{3(0.9)}-\mathrm{SnO}_{2(0.1)}$ by hydrazine method: application as an alcohol sensor. Sensor Actuat. B-Chem. Vol.81, No. 2-3, pp. 170-175.

Reeves N. J., and Mann S., 1991. Influence of inorganic additives on the tailored synthesis of iron oxides. J. Chem. Soc. Faraday Trans. Vol. 87, pp. 3875-3880.

Reimer P., and R. Weissleder, 1996. Development and experimental use of receptor specific MR contrast media. Radiology, Vol. 36, pp. 153-163.

Robins R.G., 1967. Hydrothermal precipitation in solutions of thorium nitrate, ferric nitrate and aluminium nitrate. J. Inorg. Nucl. Chem. Vol. 29, pp. 431-435.

Rockenberger J., Scher E.C., and Alivisatos A.P., 1999. A new nonhydrolytic single-precursor approach to surfactant-capped nanocrystals of transition metal oxides. J. Am. Chem. Soc. Vol. 121, pp. 11595-11596. 
Roger J., Pons J.N., Massart R., Halbreich A., and Bacri J.C., 1999. Some biomedical applications of ferrofluids. Eur.Phys. J. Appl. Phys. Vol.5, pp. 321-325.

Rice G., Tang L., Stedman K., Roberto F., Sphuler J., Gillitzer E., Johnson J. E., Douglas T., and Young M., 2004. Biological Sciences - Microbiology, Proc. Natl. Acad. Sci. U. S. A. Vol.101, pp. 7716-7720.

Safarík I., 1995. Removal of organic polycyclic compounds from water solutions with a magnetic chitosan based sorbent bearing copper phthalocyanine dye. Water Res. Vol. 29, pp.101-105.

Sahoo S.K., Mohapatra M., Pandey B., Verma H.C., Das R.P., and Anand S., 2009. Preparation and characterization of $\alpha-\mathrm{Fe}_{2} \mathrm{O}_{3}-$ $\mathrm{CeO}_{2}$ composite. Materials Characterization Vol. 60, No.5, pp. 425-431.

Sahu K.K., Rath C., Mishra N.C., Anand S., and Das R. P., 1997. Microstructural and magnetic studies on hydrothermally prepared hematite. J. Colloid Interf. Sci. Vol. 185, No. 2, pp. 402-410.

Šaric A., Nomura K., Popovic S., Ljubešic N., and Music S., 1998. Effects of urotropin on the chemical and microstructural properties of Fe-oxide powders prepared by the hydrolysis of aqueous $\mathrm{FeCl}_{3}$ solutions. Mater. Chem. Phys. Vol. 52. pp. 214220.

Schwertman U., and Taylor R.M., 1989. Iron oxides. Dixon, J.B.,Weed S.B. (Eds.), In: Minerals in Soil Environments, second ed. Soil Sci. Soc. Am. J., Medison, Wisconsin, USA, p. 379.

Schütt W., Grüttner C., Häfeli U., Zborowski M., Teller J., Putzar H., and Schümichen C., 1997. Applications of magnetic targeting in diagnosis and therapy—possibilities and limitations: a mini-review. Hybridoma,Vol. 16, pp.109-117.

Sestier C., Dasilva M.F., Sabolovic D., Roser J., and Pons J.N.,1998. Surface modification of superparamagnetic nanoparticles (Ferrofluid) studied with particle electrophoresis: Application to the specific targeting of cells. Electrophoresis Vol. 19, pp.1220-1226.

Shafi K. V. P. M., Koltypin Y., Gedanken A., Prozorov R., Balogh J., Lendvai J., Felner I., 1997. J. Phys. Chem. B, Vol. 101, pp. 6409-6414.

Sharrock M.P., and Bodnar R.E., 1985. Magnetic materials for recording: An overview with special emphasis on particles. J. Appl. Phys. Vol.57, pp. 3919.

Shin E.J., Hajaligol M.R., and Rasouli F., 2004. Heterogeneous cracking of catechol under partially oxidative conditions. Fuel Vol. 83, No.11-12, pp. 1445-1453.

Silber S., Reuter E., Stuttgen A., and Albrecht G., 2002. (In Chinese). Prog. Org. Coat. Vol.45, pp. 259-256.

Siroky K., Jiresova, J., and Hudec L., 1994. Iron oxide thin film gas sensor. Thin Solid Films Vol. 245, pp. 211-214.

Sjorgren C. E., Briley-Saebo K., Hanson M., and Johansson C.,1994. Magnetic characterization of iron oxides for magnetic resonance imaging. Magn. Reson. Med. Vol. 31, pp. 268-272.

Sohn J.R., and Lim J.S., 2006. Catalytic properties of $\mathrm{NiSO}_{4} \mathrm{ZrO}_{2}$ promoted with $\mathrm{Fe}_{2} \mathrm{O}_{3}$ for acid catalysis. Mater. Res. Bulletin, Vol.41, No.7, pp.1225-124.

Solans C., Izquierdo P., Nolla J., Azemar N., and Garcia-Celma M.J., Nano emulsions. 2005. Curr. Opin. Colloid Interf. Sci. Vol.10, pp.102-110.

Sreeram K.J., Indumathy R., Rajaram A., Nair B.U. and Ramasami T., 2006. Template synthesis of highly crystalline and monodisperse iron oxide pigments of nanosize. Materials Research Bulletin Vol.41, No.10, pp. 1875-1881.

Sugimoto T., Sakata K., 1992. Preparation of monodisperse pseudocubic $\alpha-\mathrm{Fe}_{2} \mathrm{O}_{3}$ particles from condensed ferric hydroxide gel. $J$. Colloid Interf. Sci. Vol. 152, pp. 587-590.

Sugimoto T., Sakata K., and Muramatsu A., 1993, Formation mechanism of monodisperse pseudocubic $\alpha-\mathrm{Fe}_{2} \mathrm{O}_{3}$ particles from condensed ferric hydroxide gel. J. Colloid Interf. Sci. Vol.159, No. 2, pp. 372-382.

Sujana M.G., Soma G., Vasumathi N., and Anand S., 2009. Studies on fluoride adsorption capacities of amorphous Fe/Al mixed hydroxides oxides from aqueous solutions. J. Fluorine Chem. Vol.130, No. 749-754.

Sujana M.G., and Anand S., 2010. Fluoride removal from ground waters with hydrous Fe/Al mixed hydroxides -Effect of adsorbent and other anion concentration. Applied Surf. Sci. Vol. 256, No. 23, pp. 6956-6962.

Sun S., Dorman J.L., and Fiorani D., 1992. Magnetic Properties of Fine Particles, North-Holland, Amsterdam.

Vissokov G.P., and Pirgov P.S.,1996. Plasma-chemical synthesis of ultradispersed iron oxides with pigment qualification. $J$. Mater. Sci. Vol. 31, pp. 4007-4010.

Sun S., and Zeng H., 2002. Size-controlled synthesis of magnetite nano- particles. J. Am. Chem. Soc. Vol.124, pp. 8204-8205.

Sun S., Zeng H., Robinson D. B., Raoux S., Rice P. M., Wang S. X., and Li G., 2004. Monodisperse $\mathrm{MFe}_{2} \mathrm{O}_{4}(\mathrm{M}=\mathrm{Fe}, \mathrm{Co}, \mathrm{Mn})$ nanoparticles. J. Am. Chem. Soc. Vol. 126, pp. 273-279.

Sun X., Zheng C., Zhang F., Yang Y., Wu G., Yu A., and Guan N., 2009. Size-controlled synthesis of magnetite $\left(\mathrm{Fe}_{3} \mathrm{O}_{4}\right)$ nanoparticles coated with glucose and gluconic acid from a single Fe(III) precursor by a sucrose bifunctional hydrothermal method. J. Phys. Chem. Vol.113, pp. 16002-16008.

Tan O.K., Cao W., Zhu W., Chai J.W., and Pan J.S., 2003. Ethanol sensors based on nano-sized $\alpha-\mathrm{Fe}_{2} \mathrm{O}_{3} w_{1} \mathrm{ith}^{\mathrm{SnO}} \mathrm{Z}_{2}, \mathrm{ZrO}_{2}, \mathrm{TiO}_{2}$ solid solutions. Sensor Actuat. B-Chem. Vol. 93, No.1-3, pp. 396-401.

Tao S., Liu X.Q., Chu X., and Shen Y., 1999. Preparation and properties of $\gamma-\mathrm{Fe}_{2} \mathrm{O}_{3}$ and $\mathrm{Y}_{2} \mathrm{O}_{3}$ doped $\gamma-\mathrm{Fe}_{2} \mathrm{O}_{3}$ by a sol-gel process. Sensor Actuat. B-Chem. Vol. 61, No. 1-3, pp. 33-38. 
Tartaj P., Morales M.P., Veintemillas-Verdaguer S., Gonzalez-Carreno T., and Serna, C.J., 2006. Synthesis, properties and biomedical applications of magnetic nanoparticles. Handbook of Magnetic Materials; Elsevier: Amsterdam, the Netherlands, p 403.

Thapa D., Palkar V.R., Kurup M.B., Malik S.K., 2004. Properties of magnetite nanoparticles synthesized through a novel chemical route. Mater. Lett., Vol. 58, pp. 2692-2694.

Tianshu Z., Hongmei L., Huanxing Z., Ruifang Z., and Yusheng S., 1996. Synthesis and gas-sensing characteristics of high thermostability $\gamma-\mathrm{Fe}_{2} \mathrm{O}_{3}$ powder. Sensor Actuat. B-Chem. Vol. 32, No.3, pp.181-184.

Todorovic M., Milonjic S. K., Comor J.J., and Gal I.J. 1992. Adsorption of radioactive ions ${ }_{137} \mathrm{Cs}^{+},{ }_{85} \mathrm{Sr}^{2+},{ }_{60} \mathrm{Co}^{2+}$ on natural magnetite and hematite. Sep. Sci. Technol. Vol.27, pp. 671-679.

Tominaga M., Matsumoto M., Soejima K., and Taniguchi I., 2006. Size control for two-dimensional iron oxide nanodots derived from biological molecules. J. Colloid Interf. Sci. Vol. 299, No.2, pp.761-765.

Tolbert S.H., Sieger P., Stucky G.D., Aubin S.M.J., Wu C- C., and Hendrickson D.N., 1997. Control of inorganic layer thickness in self-assembled iron oxide/surfactant composites. J. Am. Chem. Soc. Vol. 119, pp. 8652-8661.

Tourinho F.A., Franck R., and Massart R., 1990. Aqueous ferrofluids based on manganese and cobalt ferrites. J. Mater. Sci. Vol. 25, pp. 3249-3254.

Tran Nhiem, Pareta Rajesh A., Taylor Erik, and Webster Thomas J., 2010. Nanoparticles: Novel drug delivery materials for treating bone diseases. Adv.Mater. Res. (Volumes 89 - 91) 411-418. DOI:10.4028/www.scientific.net/ AMR.89-91.411 (available online).

Tronc E., Belleville P., Jolivet J.-P., Livage J., 1992. Transformation of ferric hydroxide into spinel by Fe(II) adsorption. Langmuir Vol. 8, pp. 313-319.

Tsakalakos T., 2003. NATO Sci. Ser., II: Math. Phys. Chem. (Nanostructures: Synthesis, Functional Properties and Applications). Puiblisher Kluwer Acdemy, p.1128

Uheida A., Alvarez G. S., Björkman E., Yu Z., and Muhammed M., 2006. $\mathrm{Fe}_{3} \mathrm{O}_{4}$ and $\gamma-\mathrm{Fe}_{2} \mathrm{O}_{3}$ nanoparticles for the adsorption of $\mathrm{Co}^{2+}$ from aqueous solution. J. Colloid Interf. Sci., Vol. 298, No. 2, pp. 501-507.

Vasiliev A.A., and Polykarpov M.A., 1992. Change of ferric oxide $\left(\mathrm{Fe}_{2} \mathrm{O}_{3}\right)$ semiconductor conductivity type in the interaction with reducing gases. Sensor Actuat. B-Chem. Vol. 7, No. 1-3, pp. 626-629.

Vayssie'res L., Chane'ac C., Tronc E., and Jolivet, J.-P., 1998. Size tailoring of magnetite particles formed by aqueous precipitation: An example of thermodynamic stability of nanometric oxide particles. J. Colloid Interf. Sci. Vol.205, No. 2, pp. 205-212.

Veintemillas-Verdaguer S., Morales M. P., and Serna C. J., 2001. Effect of the oxidation conditions on the maghemites produced by laser pyrolysis. Appl. Organomet. Chem. Vol. 15, pp. 365-372.

Veintemillas-Verdaguer S., Bomatí-Miguel O., and Morales M.P., 2002. Effect of the process conditions on the structural and magnetic properties of $\gamma-\mathrm{Fe}_{2} \mathrm{O}_{3}$ nanoparticles produced by laser pyrolysis. Scr. Mater. Vol.47, pp.589-593.

Veintemillas-Vendaguer S., Morales M.P., Bomati-Miguel O., Batista C., Zhao X., Bonville, P., Perez de Alejo, R., Ruiz-Cabello J., Santos M., Tendillo-Cortijo J., and Ferreiros J., 2004. Colloidal dispersions of maghemite nanoparticles produced by laser pyrolysis with applications as NMR contrast agents. J. Phys., Vol.37, pp.2054-2059.

Vidal-Vidal J., Rivas J., and Lo'pez-Quintela M.A., 2006. Synthesis of monodisperse maghemite nanoparticles by the microemulsion method. Colloids and Surfaces A: Physicochemical and Engineering Aspects Vol. 288, No.1-3, pp. 44-51.

Vijayakumar R., Koltypin Y., Felner I., and Gedanken A., 2000. Sonochemical synthesis and characterization of pure nanometersized $\mathrm{Fe}_{3} \mathrm{O}_{4}$ particles. Materials Science and Engineering A-Structural Materials Properties Microstructure and Processing Vol. 286, No.1, pp.101-105.

Walker J.S., Stragauzzi G.I., Manogue W.H., and Schuit G.C.A., 1988. Carbon monoxide and propene oxidation by iron oxides for auto-emission control. J. Catal., Vol. 110, pp. 298-309.

Wang Y.X., Hussain S.M., Krestin G.P., 2001. Superparamagnetic iron oxide contrast agents: Physicochemical characteristics and applications in MR imaging, Eur. Radiol. Vol. 11, pp. 2319-2331.

Wang X., Gao L., Zhou F., Zhang Z., M Ji., Tang C., Shen T., and Zheng H., 2004a. Large-scale synthesis of $\alpha$-LiFeO ${ }_{2}$ nanorods by low-temperature molten salt synthesis (MSS) method. J. Cryst. Growth Vol. 265, No.1-2, pp. 220-223.

Wang X., Chen X., Gao L., Zheng H., Ji M., Tang C., Shen T., and Zhang Z., 2004b. Synthesis of $\beta-\mathrm{FeOOH}_{\text {and }} \alpha-\mathrm{Fe}_{2} \mathrm{O}_{3}$ nanorods and electrochemical properties of $\beta$-FeOOH. J. Mater. Chem. Vol. 14, pp. 905-907.

Wang Chien-Tsung, and Ro Shih-Hung, 2006. Surface nature of nanoparticle gold/iron oxide aerogel catalysts J. Non-Cryst. Solids Vol.352, No.1, pp. 35-43

Wang S.F., and Tan Y.M., 2007. A novel amperometric immunosensor based on $\mathrm{Fe}_{3} \mathrm{O}_{4}$ magnetic nanoparticles/chitosan composite film for determination of ferritin. Anal. Bioanal. Chem. Vol. 387, pp. 703-708.

Weissleder R., 1996. Monocrystalline iron oxide particles for studying biological tissues. U.S. Patent No. 5,492,814.

Wirnsberger G., Gatterer K., and Behrens P., 1998. Novel synthetic pathways to layered iron(hydro)oxyhydroxide-surfactant composites. J. Mater. Chem. Vol. 8, pp.1509-1510.

Woo K., Hong J., and Ahn J.-P., 2005. Synthesis and surface modification of hydrophobic magnetite to processible magnetite@silica-propylamine. J. Magn. Magn. Mater. Vol. 293, pp.177-181. 
Wunderbaldinger P., Josephson L., and Weissleder R., 2002. Crosslinked iron oxides (CLIO): a new platform for the development of targeted MR contrast agents. Bioconjug. Chem. Vol.13, pp. 264-268.

Yang Liuqing, Xiangling Ren, Tang Fangqiong, and Zhang Lin, 2009. A practical glucose biosensor based on $\mathrm{Fe}_{3} \mathrm{O}_{4}$ nanoparticles and chitosan/nafion composite film. Biosensors and Bioelectronics Vol.25, pp. 889-895.

Yitai Q., Yi X., Chuan Jing H., L., and Zuyao C. 1994. Hydrothermal preparation and characterization of ultrafine magnetite powders. Mat. Res. Bull. Vol. 29, pp. 953-957.

Yue Jeffrey, Jiang Xuchuan, Zeng Qinghua, and Yu Aibing, 2010. Experimental and numerical study of cetyltrimethylammonium bromide (CTAB)-directed synthesis of goethite nanorods. Solid State Sciences Vol.12, pp. 1152-1159

Zhang D.E., Tong Z.W., Li S.Z., Zhang X.B., Ying A.L., 2008. Fabrication and characterization of hollow $\mathrm{Fe}_{3} \mathrm{O}_{4}$ nanospheres in a microemulsion. Mater. Lett. Vol. 62, No. 24, pp. 4053-4055.

Zhang Zhang, Zhang Qiang, Xu Li-na, and Xia Yi-ben, 2007. Preparation of nanometer $\gamma-\mathrm{Fe}_{2} \mathrm{O}_{3}$ by an electrochemical method in non-aqueous medium and reaction dynamics. Synthesis and Reactivity in Inorganic, Metal-Organic and Nano-Metal Chemistry, Vol.37, pp.53-56.

Zheng Yuan Qing, Tong ChunYi, Wang Bei, Xie Ying, Liao Hong Dong, Li Dan, and Liu Xuan Ming, 2009. Development and application of tumor-targeting magnetic nanoparticles FA-StNP@ $\mathrm{Fe}_{2} \mathrm{O}_{3}$ for hyperthermia. Chinese Sci. Bulletin Vol. 54, No. 17, pp. 2998-3004.

Zheng Y-H., Cheng Y., Bao F., and Wang Y-S, 2006. Synthesis and magnetic properties of $\mathrm{Fe}_{3} \mathrm{O}_{4}$ nanoparticles. Mater. Res. Bull., Vol.41, pp.525-529.

Zhou Q.H., Maurice P. A., and Cabaniss S. E., 2001. Size fractionation upon adsorption of fulvic acid on goethite: equilibrium and kinetic studies. Geochim. Cosmochim. Acta. Vol. 65, No. 5, pp. 803-812.

Ziolo Ronald F., Giannelis Emmanuel P., Weinstein Bernard A., O'Horo Michael P., Ganguly Bishwanath N., Mehrotra Vivek, Russell Michael W., and Huffman Donald R., 1992. Matrix-mediated synthesis of nanocrystalline $\gamma-\mathrm{Fe}_{2} \mathrm{O}_{3}$ : A new optically transparent magnetic material. Vol. 257, pp.219-223.

\section{Biographical notes}

M. Mohapatra holds Ph.D. from Utkal University. She, is scientist at Hydro-Electro Metallurgy Department of Institute of Minerals and Materials Technology, Bhubaneswar, India. She has developed expertise in synthesis of various iron phases of iron oxides/hydroxides using variety of techniques which include chemical precipitation, surfactant mediation, hydrothermal and micro-emulsion. Her fields of interest are: hydrometallurgy, synthesis of nano materials which include iron, cerium, titanium oxides and barium titanates.

S. Anand obtained her Ph.D degree from Indian Institute of Technology, Delhi in 1977. She is Adjunct Professor, Faculty of Minerals and Energy, Murdoch University, Western Australia since May 2009. She had worked at Institute of Minerals and Materials Technology, India, for thirty two years in different positions and superannuated in December 2008. Her area of interest are: hydrometallurgy, high pressure leaching, nano material synthesis and their application, mitigation of toxic ions from aqueous solution by adsorption technique.

Received August 2010

Accepted November 2010

Final acceptance in revised form November 2010 